\title{
Breast cancer and hormonal contraceptives: collaborative reanalysis of individual data on 53,297 women with breast cancer and 100,239 women without breast cancer from 54 epidemiological studies
}

Citation for published version (APA):

van den Brandt, P. A., Goldbohm, R. A., \& Collaborative Group on Hormona, L. F. (1996). Breast cancer and hormonal contraceptives: collaborative reanalysis of individual data on 53,297 women with breast cancer and 100,239 women without breast cancer from 54 epidemiological studies. Lancet, 347, 17131727. https://doi.org/10.1016/S0140-6736(96)90806-5

Document status and date:

Published: 01/01/1996

DOI:

10.1016/S0140-6736(96)90806-5

Document Version:

Publisher's PDF, also known as Version of record

Please check the document version of this publication:

- A submitted manuscript is the version of the article upon submission and before peer-review. There can be important differences between the submitted version and the official published version of record. People interested in the research are advised to contact the author for the final version of the publication, or visit the DOI to the publisher's website.

- The final author version and the galley proof are versions of the publication after peer review.

- The final published version features the final layout of the paper including the volume, issue and page numbers.

Link to publication

\footnotetext{
General rights rights.

- You may freely distribute the URL identifying the publication in the public portal. please follow below link for the End User Agreement:

www.umlib.nl/taverne-license

Take down policy

If you believe that this document breaches copyright please contact us at:

repository@maastrichtuniversity.nl

providing details and we will investigate your claim.
}

Copyright and moral rights for the publications made accessible in the public portal are retained by the authors and/or other copyright owners and it is a condition of accessing publications that users recognise and abide by the legal requirements associated with these

- Users may download and print one copy of any publication from the public portal for the purpose of private study or research.

- You may not further distribute the material or use it for any profit-making activity or commercial gain

If the publication is distributed under the terms of Article 25fa of the Dutch Copyright Act, indicated by the "Taverne" license above,

Download date: 26 Apr. 2023 


\section{Breast cancer and hormonal contraceptives: collaborative reanalysis of individual data on 53297 women with breast cancer and 100239 women without breast cancer from 54 epidemiological studies}

\section{Collaborative Group on Hormonal Factors in Breast Cancer*}

\section{Summary}

Background The Collaborative Group on Hormonal Factors in Breast Cancer has brought together and reanalysed the worldwide epidemiological evidence on the relation between breast cancer risk and use of hormonal contraceptives.

Methods Individual data on 53297 women with breast cancer and 100239 women without breast cancer from 54 studies conducted in 25 countries were collected, checked, and analysed centrally. Estimates of the relative risk for breast cancer were obtained by a modification of the Mantel-Haenszel method. All analyses were stratified by study, age at diagnosis, parity, and, where appropriate, the age a woman was when her first child was born, and the age she was when her risk of conception ceased.

Findings The results provide strong evidence for two main conclusions. First, while women are taking combined oral contraceptives and in the 10 years after stopping there is a small increase in the relative risk of having breast cancer diagnosed (relative risk $[95 \% \mathrm{Cl}]$ in current users 1.24 [1.15-1.33], 2p<0.00001; $1-4$ years after stopping 1.16 $[1.08-1 \cdot 23], 2 \mathrm{p}=0.00001 ; 5-9$ years after stopping 1.07 $[1.02-1 \cdot 13], 2 p=0.009)$. Second, there is no significant excess risk of having breast cancer diagnosed 10 or more years after stopping use (relative risk 1.01 [0.96-1.05], NS). The cancers diagnosed in women who had used combined oral contraceptives were less advanced clinically than those diagnosed in women who had never used these contraceptives: for ever-users compared with never-users, the relative risk for tumours that had spread beyond the breast compared with localised tumours was 0.88 $(0.81-0.95 ; 2 p=0.002)$. There was no pronounced variation in the results for recency of use between women with different background risks of breast cancer, including women from different countries and ethnic groups, women with different reproductive histories, and those with or without a family history of breast cancer. The studies included in this collaboration represent about $90 \%$ of the epidemiological information on the topic, and what is known about the other studies suggests that their omission has not materially affected the main conclusions.

* Collaborators listed at end of article

Correspondence to: Secretariat, Collaborative Group on Hormonal Factors in Breast Cancer, ICRF Cancer Epidemiology Unit, Gibson Building, Radcliffe Infirmary, Oxford OX2 $6 \mathrm{HE}$, UK
Other features of hormonal contraceptive use such as duration of use, age at first use, and the dose and type of hormone within the contraceptives had little additional effect on breast cancer risk, once recency of use had been taken into account. Women who began use before age 20 had higher relative risks of having breast cancer diagnosed while they were using combined oral contraceptives and in the 5 years after stopping than women who began use at older ages, but the higher relative risks apply at ages when breast cancer is rare and, for a given duration of use, earlier use does not result in more cancers being diagnosed than use beginning at older ages.

Because breast cancer incidence rises steeply with age, the estimated excess number of cancers diagnosed in the period between starting use and 10 years after stopping increases with age at last use: for example, among 10000 women from Europe or North America who used oral contraceptives from age 16 to 19 , from age 20 to 24 , and from age 25 to 29, respectively, the estimated excess number of cancers diagnosed up to 10 years after stopping use is $0.5(95 \% \mathrm{Cl} 0.3-0.7), 1.5(0.7-2.3)$, and 4.7 $(2 \cdot 7-6 \cdot 7)$. Up to 20 years after cessation of use the difference between ever-users and never-users is not so much in the total number of cancers diagnosed, but in their clinical presentation, with the breast cancers diagnosed in ever-users being less advanced clinically than those diagnosed in never-users.

The relation observed between breast cancer risk and hormone exposure is unusual, and it is not possible to infer from these data whether it is due to an earlier diagnosis of breast cancer in ever-users, the biological effects of hormonal contraceptives, or a combination of reasons.

Interpretation Women who are currently using combined oral contraceptives or have used them in the past 10 years are at a slightly increased risk of having breast cancer diagnosed, although the additional cancers diagnosed tend to be localised to the breast. There is no evidence of an increase in the risk of having breast cancer diagnosed 10 or more years after cessation of use, and the cancers diagnosed then are less advanced clinically than the cancers diagnosed in never-users.

Lancet 1996; 347: 1713-27

See Editorial page 1707

\section{Introduction}

The use of female sex hormones as contraceptives began in 1960, since when an estimated 200 million women 


\begin{tabular}{|c|c|c|c|c|c|c|c|}
\hline \multirow{2}{*}{$\begin{array}{l}\text { Median } \\
\text { year of } \\
\text { dlagnosis }\end{array}$} & \multirow[b]{2}{*}{ Study } & \multicolumn{2}{|c|}{$\begin{array}{l}\text { Pombined oral contraceptive use } \\
\text { Ever } \\
\text { Never }\end{array}$} & \multicolumn{2}{|c|}{ Statlstics } & \multicolumn{2}{|c|}{$\begin{array}{l}\text { Relative risk of breast cancer } \\
\text { in ever-users versus never-users }\end{array}$} \\
\hline & & Cases/Controls & Cases/Controls & (O-E) & $\operatorname{var}(O-E)$ & 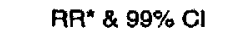 & $\mathrm{RR}^{*} \pm \mathrm{SD}$ \\
\hline \multicolumn{8}{|c|}{ PROSPECTIVE STUDIES } \\
\hline 1980 & $\operatorname{RCGP}^{15}$ & $198 / 728$ & $128 / 576$ & 13.0 & $55 \cdot 6$ & & $1 \cdot 26 \pm 0.151$ \\
\hline 1982 & Oxford/FPA ${ }^{26}$ & $96 / 437$ & $101 / 342$ & -9.7 & $26.6-$ & & $0.69 \pm 0.162$ \\
\hline 1985 & NursesHealth ${ }^{22}$ & $1105 / 4243$ & $1645 / 6703$ & 35.6 & 431.0 & & $109 \pm 0050$ \\
\hline 1985 & CanadianNBSS $^{37}$ & $741 / 2905$ & $594 / 2418$ & 11.5 & $209 \cdot 2$ & & $106 \pm 0.071$ \\
\hline 1987 & AmerCancSoc ${ }^{42}$ & $264 / 1091$ & $907 / 3671$ & 1.5 & 93.4 & & $1.02 \pm 0.104$ \\
\hline \multirow[t]{2}{*}{1988} & Nethertands Cohort ${ }^{4 B}$ & $105 / 408$ & $348 / 1248$ & 2.9 & 46.1 & & $1.06 \pm 0.152$ \\
\hline & Other $r^{5,11,14,19}$ & $138 / 431$ & $436 / 1576$ & 2.5 & $25 \cdot 4$ & & $110 \pm 0 \cdot 208$ \\
\hline \multicolumn{2}{|c|}{ All prospective studies } & $2647 / 10243$ & $4159 / 16534$ & $57 \cdot 3$ & 887.3 & & $1.07 \pm 0.035$ \\
\hline \multicolumn{8}{|c|}{ CASE-CONTROL STUDIES, WITH POPULATION CONTROLS } \\
\hline 1976 & Brinton ${ }^{24}$ & $714 / 781$ & $2503 / 2764$ & 14.0 & 193.7 & & $1.07 \pm 0075$ \\
\hline 1980 & Bernstein/Pike ${ }^{3,27}$ & $373 / 369$ & $66 / 70$ & 03 & 213 & & $1.01 \pm 0.218$ \\
\hline 1981 & Hislop ${ }^{8}$ & $370 / 414$ & $579 / 535$ & -50 & 51.5 & ! & $0.91 \pm 0133$ \\
\hline 1981 & $\mathrm{CASH}^{34}$ & $2815 / 2872$ & $1879 / 1784$ & $-27 \cdot 9$ & 394.7 & & $0.93 \pm 0.049$ \\
\hline 1983 & UKNational $^{25}$ & $684 / 673$ & $71 / 82$ & 59 & 31.2 & & $1.20 \pm 0.197$ \\
\hline 1983 & Bain/Sıskind $^{23}$ & $197 / 424$ & $343 / 671$ & $-3 \cdot 9$ & 31.6 & 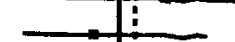 & $088 \pm 0.167$ \\
\hline 1983 & Ewertz & $479 / 458$ & $1066 / 941$ & $-4 \cdot 0$ & 80.8 & & $0.95 \pm 0.109$ \\
\hline 1984 & Meirik/Lund $^{9}$ & 289/338 & $133 / 189$ & 8.7 & 420 & & $1.23 \pm 0.171$ \\
\hline 1984 & Long Island ${ }^{33}$ & $266 / 230$ & $914 / 950$ & 13.8 & 57.2 & & $1.27 \pm 0.149$ \\
\hline 1984 & Clarke $e^{38}$ & $257 / 543$ & $350 / 669$ & -4.0 & 47.8 & & $0.92 \pm 0.139$ \\
\hline 1985 & Yu/Yuan/Wang ${ }^{18,40}$ & $184 / 180$ & $650 / 654$ & 6.7 & $44 \cdot 0$ & & $1.16 \pm 0.163$ \\
\hline 1985 & Paul/Skegg ${ }^{28}$ & $674 / 1521$ & $217 / 343$ & 4.5 & $69 \cdot 2$ & & $1.07 \pm 0.124$ \\
\hline 1987 & Daling $^{50}$ & $685 / 875$ & $62 / 86$ & -00 & 26.5 & & $1.00 \pm 0.194$ \\
\hline 1988 & 4 StateStudy ${ }^{47}$ & $2427 / 3726$ & $4443 / 5793$ & $8 \cdot 9$ & $416 \cdot 6$ & & $1.02 \pm 0.050$ \\
\hline 1988 & Rookus/van Leeuven ${ }^{49}$ & $781 / 782$ & $137 / 136$ & 25 & 40.0 & & $1.07 \pm 0.163$ \\
\hline 1989 & Yang/Gallagher ${ }^{41}$ & $407 / 441$ & $609 / 584$ & $-15 \cdot 3$ & $55 \cdot 1$ & & $0.76 \pm 0.118$ \\
\hline 1989 & Primic-Zakelj $^{48}$ & $296 / 297$ & $323 / 322$ & 3.0 & 581 & & $1.05 \pm 0.135$ \\
\hline \multirow[t]{2}{*}{1991} & WISH ${ }^{53}$ & $+532 / 1597$ & $334 / 412$ & 20.5 & $119 \cdot 8$ & & $1.19 \pm 0.100$ \\
\hline & Other ${ }^{2,10,12,17,21,39,52}$ & $1563 / 2029$ & $1417 / 2141$ & $16 \cdot 3$ & 168.5 & & $1 \cdot 10 \pm 0.081$ \\
\hline \multicolumn{2}{|c|}{$\begin{array}{l}\text { All case-control studies, with } \\
\text { population controls }\end{array}$} & $\begin{array}{r}14993 / 18550 \\
\text { HOSPITAL CON }\end{array}$ & $\begin{array}{l}16096 / 19126 \\
\text { OLS }\end{array}$ & $44 \cdot 8$ & 1949.6 & & $1.02 \pm 0.023$ \\
\hline 1980 & Vessey $y^{4,13}$ & $963 / 972$ & $1420 / 1419$ & 8.5 & 193.4 & & $1.04 \pm 0.074$ \\
\hline 1981 & Ravnihar ${ }^{16}$ & $161 / 460$ & $370 / 1479$ & $26 \cdot 6$ & $59 \cdot 2$ & & $1.57 \pm 0.163$ \\
\hline \multirow[t]{2}{*}{1983} & WHO(developing) ${ }^{30}$ & $525 / 5117$ & $1180 / 9936$ & 27.6 & $177 \cdot 1$ & & $1.17 \pm 0.081$ \\
\hline & WHO (developed) ${ }^{30}$ & $667 / 1933$ & $922 / 2116$ & 10.9 & 157.6 & & $1.07 \pm 0.082$ \\
\hline 1986 & Clavel $^{31}$ & $247 / 424$ & $248 / 472$ & 8.6 & $44 \cdot 1$ & & $1.21 \pm 0.166$ \\
\hline 1987 & LaVecchia $^{45}$ & $366 / 238$ & $2897 / 2490$ & 30.2 & 94.1 & & $1.38 \pm 0.121$ \\
\hline \multirow[t]{2}{*}{1992} & Franceschi $^{51}$ & $382 / 314$ & $2187 / 2274$ & $25 \cdot 3$ & 104.7 & & $1.27 \pm 0.111$ \\
\hline & Other $r^{6,7,20,29,32,36,43,44}$ & $616 / 1378$ & $1879 / 3543$ & $10 \cdot 1$ & $102 \cdot 5$ & & $1 \cdot 10 \pm 0 \cdot 104$ \\
\hline \multicolumn{2}{|c|}{$\begin{array}{l}\text { All case-control studies, with } \\
\text { hospital controls }\end{array}$} & $3927 / 10836$ & $11103 / 23729$ & 147.8 & 932.7 & & $1.17 \pm 0.035$ \\
\hline \multirow[t]{2}{*}{ ALL $\mathbf{S}$} & TUDIES. & $21567 / 39629$ & $31358 / 59389$ & 249.8 & 3769.6 & 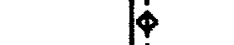 & $1.07 \pm 0.017$ \\
\hline & & & & & 0.0 & 1.0 & .0 \\
\hline
\end{tabular}

Test for heterogeneity between study designs: $X^{2}(2 \mathrm{df})=11 \cdot 6 ; p=0.003$

Test for heterogeneity between studies: $X^{2}(33 \mathrm{df})=51.8 ; p=0.02$

\section{Figure 1: Relative risk of breast cancer in ever-users compared with never-users of combined oral} contraceptives

Separate results are given for individual studies. Each relative risk and its $99 \% \mathrm{Cl}$ is plotted as a black square and a line. The area of the square is proportional to the amount of statistical information (ie, to the inverse of the variance of the logarithm of the relative risk). Diamonds indicate $99 \% \mathrm{Cls}$ for totals. The solıd vertical line represents a relative risk of 1.0 and the broken vertical line indicates the overall relative risk estimate for all studies combined.

* Relative risk (given with $99 \% \mathrm{Cl}$ ) relative to never-users, stratified by study, age at diagnosis, parity, and, where appropriate, the age a woman was when her first chıld was born and the age she was when her risk of conception ceased.

throughout the world have used them. ${ }^{1}$ The most widely used type of hormonal contraceptive has been the combined oral contraceptive, which contains an oestrogen and progestagen and is prepared from various compounds in various doses and combinations. Other hormonal contraceptives contain progestagen only, given orally or by injection. Many epidemiological studies have investigated whether hormonal contraceptives might affect breast cancer risk, ${ }^{2-6 \bar{j}}$ and the Collaborative Group on Hormonal Factors in Breast Cancer was set up in 1992 to bring together, reanalyse, and publish the worldwide data. The main results are summarised here. Additional results, together with full descriptions of the methods, the studies and the women included, are being published elsewhere ${ }^{66}$

\section{Methods}

\section{Identification of studies and collection of data}

Epidemiological studies that included at least 100 women with breast cancer and that obtained information on the use of hormonal contraceptives and on reproductive history were eligible for inclusion. Studies were identified from review articles, from computer-aided literature searches, and from discussions with colleagues. Special efforts were made to identify all studies that included relevant information, irrespective of whether results on hormonal contraceptives had been published. The principal investigators of all studies identified were invited to collaborate. Subsequently a list of studies and references was sent to collaborators and they were asked if they knew of further studies that were not listed; the principal investigators of those studies 
a: Relative risk of breast cancer by total duration of use of combined oral contraceptives

Total duration
of use

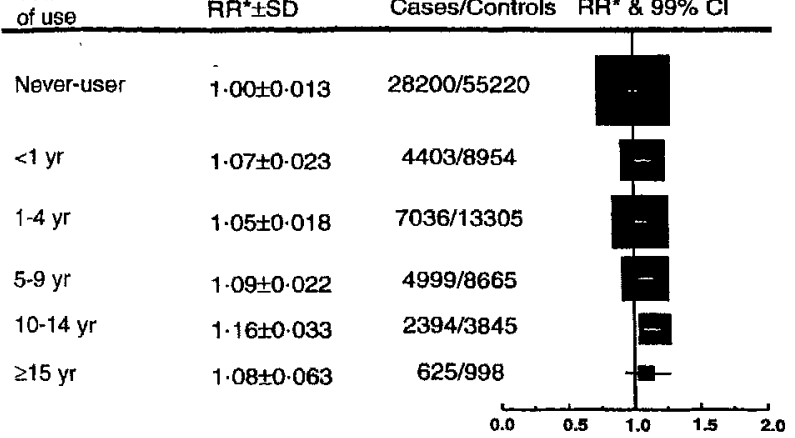

Test for heterogeneity within users: $X^{2}(4 \mathrm{df})=8 \cdot 0$; NS

Test for trend within users: $X^{2}(1 \mathrm{df})=3 \cdot 9 ; \mathrm{p}=0.05$

c: Relative risk of breast cancer by time since first use of combined oral contraceptives Time since first

\begin{tabular}{lll} 
use & $\mathrm{RR}^{*} \pm \mathrm{SD}$ & Cases/Controls \\
\hline
\end{tabular}

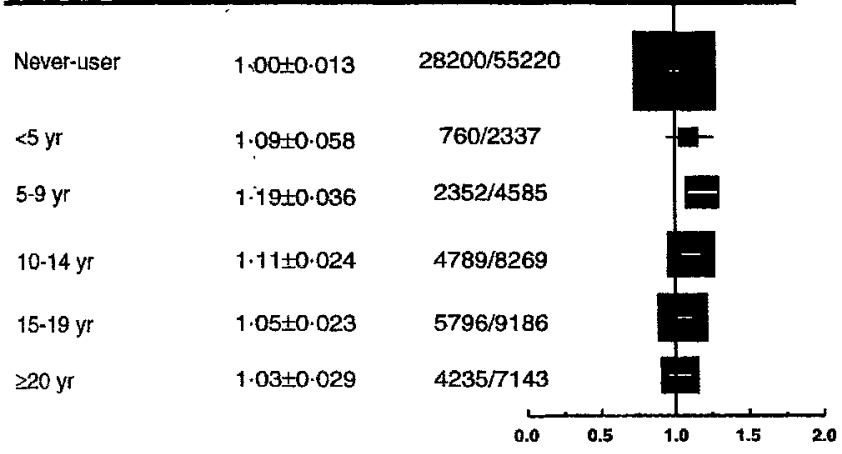

Test for heterogeneity within users: $X^{2}(4 d f)=13.4 ; p=001$ Test for trend within users: $X^{2}(1 \mathrm{df})=9 \cdot 6 ; p=0.002$ b: Relative risk of breast cancer by age at

first use of combined oral contraceptives

Age at flrst use $\quad \mathrm{RH}^{*} \pm \mathrm{SD} \quad$ Cases/Controls $\mathrm{RR}^{*} \& 99 \% \mathrm{Cl}$

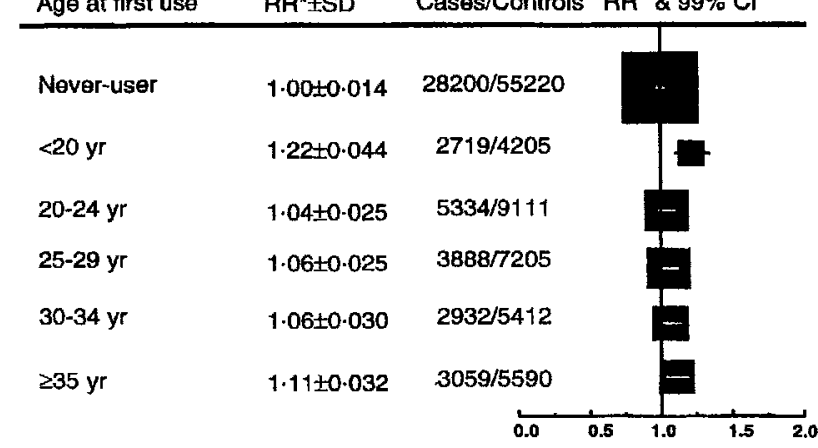

Test for heterogeneity within users: $X^{2}(4 d f)=13.4, p=0.01$

Test for trend within users: $\mathrm{X}^{2}(1 \mathrm{df})=0.2$; NS

d: Relative risk of breast cancer by time since

last use of combined oral contraceptives

Time since last

use $\quad \mathrm{RR}^{*} \pm \mathrm{SD}$ Cases/Controls $\mathrm{RR}^{*} \& 99 \% \mathrm{Cl}$

Never-user $\quad 1.00 \pm 0.014 \quad 28200 / 5522$

Current user $\quad 1 \cdot 24 \pm 0.038 \quad 2356 / 4328$

$\begin{array}{lll}1-4 \mathrm{yr} & 1.16 \pm 0.032 & 2717 / 4851\end{array}$

$\begin{array}{lll}5-9 \text { yr } & 1.07 \pm 0.024 & 4239 / 7688\end{array}$

$10-14 \mathrm{yr} \quad 0.98 \pm 0.022 \quad 4384 / 8182$

$\geq 15 \mathrm{yr}$

$1.03 \pm 0.025$

$4434 / 8285$

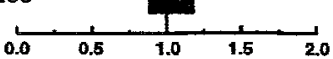

Test for heterogeneity within users: $X^{2}(4 \mathrm{df})=41.5 ; p<0.00001$

Test for trend within users: $X^{2}(t$ df $)=31.7 ; p<0.00001$

Figure 2: Relative risk of breast cancer for various indices of timing of use of combined oral contraceptives

Each analysis includes aggregated data from all studies. Variance calculations are based on floating absolute risks ${ }^{71}$

which ascribe an appropriate varıance not only to the relative risk for each category of use but also to the relative risk of 1.0 for never-users. The area of each square is proportional to the amount of statistical information and $\mathrm{Cls}$ are drawn as white lines when they are so narrow that they lie entirely within the width of the square.

*Relative risk (given with $99 \% \mathrm{Cl}$ ) relative to never-users, stratıfied by study, age at diagnosis, parıty, and, where appropriate, the age a woman was when her first child was born and the age she was when her risk of conception ceased.

were also invited to collaborate. Few additional studies came to light from such enquiries, and in view of the wide consultation it seems unlikely that any substantial ones have been missed. Of the eligible studies identified, ${ }^{2-65}$ original data were available for this analysis from 54 , of which 52 have been published. ${ }^{2-53}$ Original data could not be retrieved for 11 studies $^{54-64}$ and one research group declined to take part in the collaboration. ${ }^{65}$

Data for individual women were sought on sociodemographic factors, use of hormonal contraceptives and hormone replacement therapy, family history of breast cancer, height, weight, age at menarche, reproductive history, menopausal status, age at menopause, gynaecological surgery, and alcohol consumption. Information on tumour spread was sought for women with breast cancer. Similar data were sought from prospective studies and from case-control studies. Prospective studies were included by means of a nested case-control design, with four randomly matched controls for each woman with breast cancer. ${ }^{56}$ The availability of data on individual women permitted a wide range of consistency checks to be made. Apparent inconsistencies, implausibilities, or omissions were clarified with collaborators and, where appropriate, rectified. Summary tables and listing of the variables used in these analyses were supplied to the investigators for checking.

Information on hormonal contraceptives, reproductive factors, and tumour stage had been collected in fairly comparable ways in most studies, or could be derived simply, so that use of similar definitions across all studies was generally straightforward. The only material difference between the studies was in the recording of durations of use of less than a year, so analyses were repeated with ever-users defined as women with durations of use of more than a year, but this approach made little difference to the main findings. ${ }^{66}$ Information on the type and dose of oestrogen and of progestagen in the hormonal contraceptive that each woman had used first, had used last, and had used for the longest period of time was available for 27 studies $33,4,9,10,12,13,15,18,24-26,28,30,33,34,37,38,40,41,48-53$ (and the two unpublished studies). Preparations were grouped into three broad categories of dose-low, medium, and high (containing $<50 \mu \mathrm{g}, 50 \mu \mathrm{g},>50 \mu \mathrm{g}$, oestrogen, respectively; this classification scheme is strongly correlated with progestagen dose as well as with oestrogen dose. ${ }^{66}$ Only invasive breast cancers were included in these analyses, and information that permitted their classification into cancers that were localised to the breast and those that had spread to axillary lymph nodes or to distant sites was available for 24 studies (and the two unpublished studies). . $^{2,4,8,16,20-23,25,30-35,37,43,48-50,52,53}$

\section{Statistical analysis}

Data from different studies are combined by the Mantel-Haenszel stratification technique. ${ }^{.7}$ To ensure that women in one study are compared directly only with similar women in the same study, all analyses are stratified by study, as well as by other factors, described below. The stratum-specific quantities that are calculated are the standard observed minus expected $(\mathrm{O}-\mathrm{E})$ numbers of women with breast cancer, together with their variances, $\operatorname{var}(\mathrm{O}-\mathrm{E})$, and covariances..$^{66,69}$ Use of these simple stratified $\mathrm{O}-\mathrm{E}$ values in preference to more complex mathematical models sacrifices some statistical power but has the advantage of avoiding assumptions about the precise forms of any relations in the data.

The stratified $\mathrm{O}-\mathrm{E}$ values, together with their variances and covariances, yield both statistical tests ( $p$ values) and statistical descriptions (odds ratios, subsequently referred to as relative 
a: Relative risk of breast cancer by duration of use and time since last use of combined oral contraceptives

\begin{tabular}{|c|c|c|c|}
\hline & $\mathrm{RP}^{*} \pm \mathrm{SD}$ & Cases/Controls & $\mathrm{RA}^{*} \& 99 \% \mathrm{Cl}$ \\
\hline NEVER-USER & $1.00 \pm 0.014$ & $28200 / 55220$ & \\
\hline \multicolumn{4}{|l|}{ CURRENT USER } \\
\hline Duration $\leq 12$ mo & $1.18 \pm 0.122$ & $176 / 621$ & \\
\hline $1-4 \mathrm{yr}$ & $1.27 \pm 0.079$ & $489 / 1158$ & \\
\hline $5-9 \mathrm{yr}$ & $121 \pm 0061$ & $794 / 1338$ & \\
\hline$\geq 10 \mathrm{yr}$ & $1.29 \pm 0060$ & $882 / 1156$ & \\
\hline \multicolumn{4}{|c|}{ LAST USE 1-4 YEARS AGO } \\
\hline Duration $\leq 12 \mathrm{mo}$ & $1.05 \pm 0.080$ & $359 / 1021$ & \\
\hline $1-4 \mathrm{yr}$ & 11240064 & $649 / 1240$ & \\
\hline $5-9 \mathrm{yr}$ & $1.26 \pm 0.059$ & $908 / 1369$ & \\
\hline$\geq 10 \mathrm{yr}$ & $1.14 \pm 0060$ & $746 / 1045$ & \\
\hline \multicolumn{4}{|c|}{ LAST USE 5-9 YEARS AGO } \\
\hline Duration $\leq 12 \mathrm{mo}$ & $105+0056$ & $757 / 1712$ & \\
\hline $1-4 \mathrm{yr}$ & $1.05 \pm 0.043$ & $1280 / 2186$ & \\
\hline $5-9$ yr & $113 \pm 0044$ & $1340 / 2067$ & \\
\hline$\geq 10 \mathrm{yr}$ & $1.14 \pm 0062$ & $714 / 1060$ & \\
\hline \multicolumn{4}{|c|}{ LAST USE 10-14 YEARS AGO } \\
\hline Duration $\leq 12 \mathrm{mo}$ & $1.00 \pm 0.044$ & $1160 / 2337$ & \\
\hline $1.4 \mathrm{yr}$ & $0.97 \pm 0037$ & $1581 / 2639$ & \\
\hline $5-9 \mathrm{yr}$ & $0.99 \pm 0.046$ & $1075 / 1681$ & \\
\hline$\geq 10 \mathrm{yr}$ & $1.01 \pm 0083$ & $332 / 598$ & \\
\hline \multicolumn{4}{|c|}{ LAST USE $\geq 15$ YEARS AGO } \\
\hline Duration $\leq 12 \mathrm{mo}$ & $105 \pm 0.036$ & $1999 / 3470$ & \\
\hline $1-4 \mathrm{yr}$ & $104 \pm 0.041$ & $1533 / 2574$ & \\
\hline $5-9$ yr & $087 \pm 0.064$ & $483 / 946$ & \\
\hline$\geq 10 \mathrm{yr}$ & $090 \pm 0146$ & $83 / 196$ & \\
\hline
\end{tabular}

b: Relative risk of breast cancer by age at first use and time since last use of combined ora contraceptives

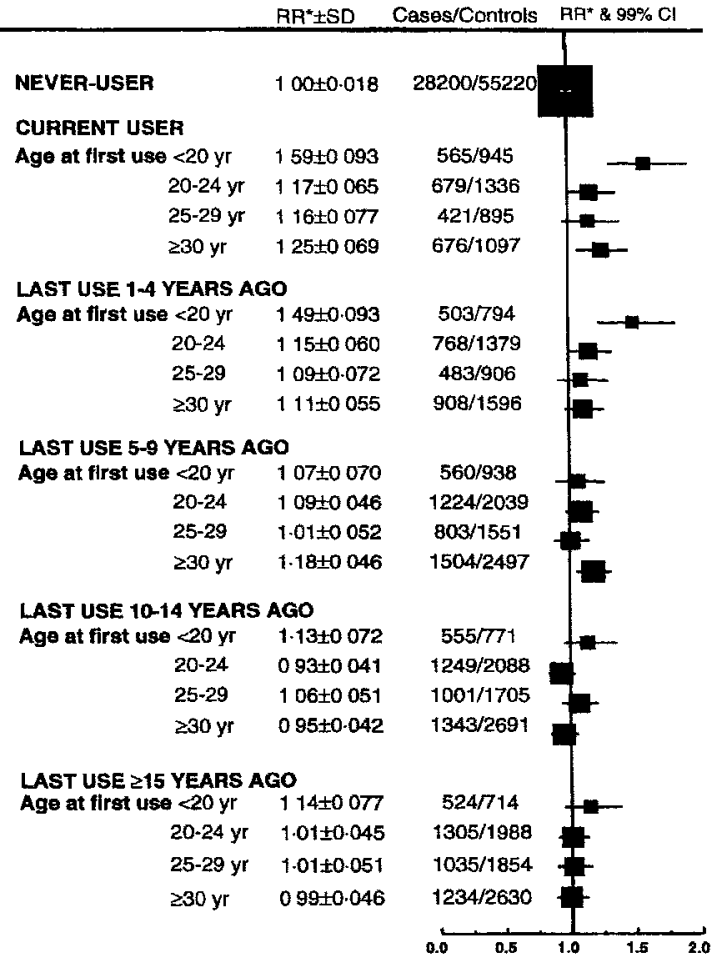

c: Relative risk of breast cancer by time since firs use and time since last use of combined oral contraceptives

\begin{tabular}{|c|c|c|c|}
\hline & $\mathrm{RR}^{*} \pm \mathrm{SD}$ & Cases/Controls & $\mathrm{RP}^{*} \& 99 \% \mathrm{Cl}$ \\
\hline NEVER-USER & $1.00 \pm 0015$ & $28200 / 55220$ & \\
\hline \multicolumn{4}{|l|}{ CURRENT USER } \\
\hline First use $<10 \mathrm{yr}$ ago & $122 \pm 0058$ & 947/2390 & \\
\hline 10-14 yr ago & $134 \pm 0065$ & $823 / 1163$ & \\
\hline 15-19 yr ago & $1.18 \pm 0079$ & $461 / 588$ & \\
\hline$\geq 20$ yr ago & $1 \cdot 18 \pm 0165$ & $110 / 132$ & \\
\hline \multicolumn{4}{|c|}{ LAST USE 1-4 YEARS AGO } \\
\hline First use $<10$ yr ago & $1-12 \pm 0054$ & $967 / 2180$ & \\
\hline $10-14$ yr ago & $1.23 \pm 0.059$ & $869 / 1350$ & \\
\hline $15-19$ уг ago & $116 \pm 0.066$ & $650 / 902$ & \\
\hline $220 \mathrm{yr}$ ago & $111 \pm 0121$ & $176 / 243$ & \\
\hline \multicolumn{4}{|c|}{ LAST USE 5-9 YEARS AGO } \\
\hline First use < 10 yr ago & $112+0053$ & $941 / 1915$ & \\
\hline to-14 yr ago & $111 \pm 0.043$ & $1424 / 2416$ & \\
\hline 15-19 yr ago & $1 \cdot 10 \pm 0045$ & $1246 / 1894$ & \\
\hline$\geq 20$ yr ago & $0.97 \pm 0.068$ & $480 / 800$ & \\
\hline \multicolumn{4}{|c|}{$\begin{array}{l}\text { LAST USE } 10-14 \text { YEARS AGO } \\
\text { First use }<10 \text { yr ago } \quad \text { Not applicable }\end{array}$} \\
\hline $10-14 \mathrm{yr}$ ago & $0.95 \pm 0038$ & $1433 / 2876$ & \\
\hline $15-19$ yr ago & $1 \cdot 01 \pm 0036$ & 1739/2785 & \\
\hline$\geq 20 \mathrm{yr}$ ago & $0.99+0049$ & 976/1594 & \\
\hline \multicolumn{4}{|c|}{ LAST USE $\geq 15$ YEARS AGO } \\
\hline First use $<15$ yr ago & Not applicabt & & \\
\hline 15-19 yr ago & $098 \pm 0038$ & $1523 / 2672$ & \\
\hline \multirow[t]{2}{*}{$\geqslant 20$ yr ago } & $103 \pm 0034$ & $2575 / 4513$ & \\
\hline & & 0.0 & o \\
\hline
\end{tabular}

Figure 3: Relative risk of breast cancer for various indices of the timing of combined oral contraceptive use within categories of time since last use

Format as in figure 2. Of 15 tests for heterogeneity, one within each time since last use category, two are statistically significant: age at first use in current users $\left(x^{2}=12 \cdot 7, \mathrm{df}=3, \mathrm{p}=0.005\right)$ and age at first use in women whose last use was $1-4$ years ago $\left(\chi^{2}=12.6, \mathrm{df}=3, \mathrm{p}=0.006\right)$.

* Relative risk (given with $99 \% \mathrm{Cl}$ ) relative to never-users, stratified by study, age at diagnosis, parity, and, where appropriate, the age a woman was when her first child was born and the age she was when her risk of conception ceased.

risks). Relative risk estimates are obtained from $\mathrm{O}-\mathrm{E}$ values by the one-step method that has been widely used in overviews of clinical trials. ${ }^{70}$ Although this method may not be appropriate for estimating relative risks of two-fold or greater, it should satisfactorily estimate less extreme relative risks; when the main analyses were repeated by maximum likelihood methods, the results were virtually identical. ${ }^{66}$ In analyses involving comparisons of more than two groups, the confidence intervals associated with these relative risks are estimated by treating the relative risks as floating absolute risks. ${ }^{71}$ The use of floating absolute risks does not alter the relative risk estimates, but it reduces the variances attributed to them and reduces unwanted covariances between the groups. This approach also attributes an appropriate variance estimate to the group arbitrarily chosen as the baseline group-ie, the group with relative risk set to one.

All analyses are routinely stratified by study, by centre within study for multicentre studies, and by fine divisions of age $(16,17$, $18 \ldots 63,64,65-69,70-74,75-79,80-84,85-89)$. Of the remaining variables that might confound the relation between breast cancer risk and oral contraceptive use, reproductive history and age at which a woman ceases to be at risk of conception are particularly important; other factors that were considered, such as family history, ethnic group, or weight, do not confound the main relations. ${ }^{66}$ The basic stratification procedure, therefore, also included one variable representing reproductive history (nulliparous women formed a separate stratum, and parous women were cross-classified according to three divisions of age at first birth: $<20,20-29, \geqslant 30$; and two divisions of parity; $1-2, \geqslant 3$ ) and a second variable representing the age at which a woman ceased to be at risk of conception (taken to be the youngest age at which hysterectomy, tubal ligation, bilateral oophorectomy, or natural menopause occurred, and categorised as: still at risk of conception, <35, 35-39, 40-44, 45-49, $\geqslant 50$ ). Women with unknown values for a particular stratification variable were allocated to a separate stratum.

\section{Presentation of results}

For many analyses, results are presented in the form of plots of adjusted relative risks. Because of the large number of estimates involved, $99 \% \mathrm{CI}$ are used in most instances, with $95 \% \mathrm{CI}$ used only for summarising the main findings. Each relative risk is plotted as a black square, the area of which is inversely proportional to the variance of the logarithm of the estimate, and is hence an indication of the amount of statistical information available for that particular estimate. The corresponding $99 \% \mathrm{CI}$

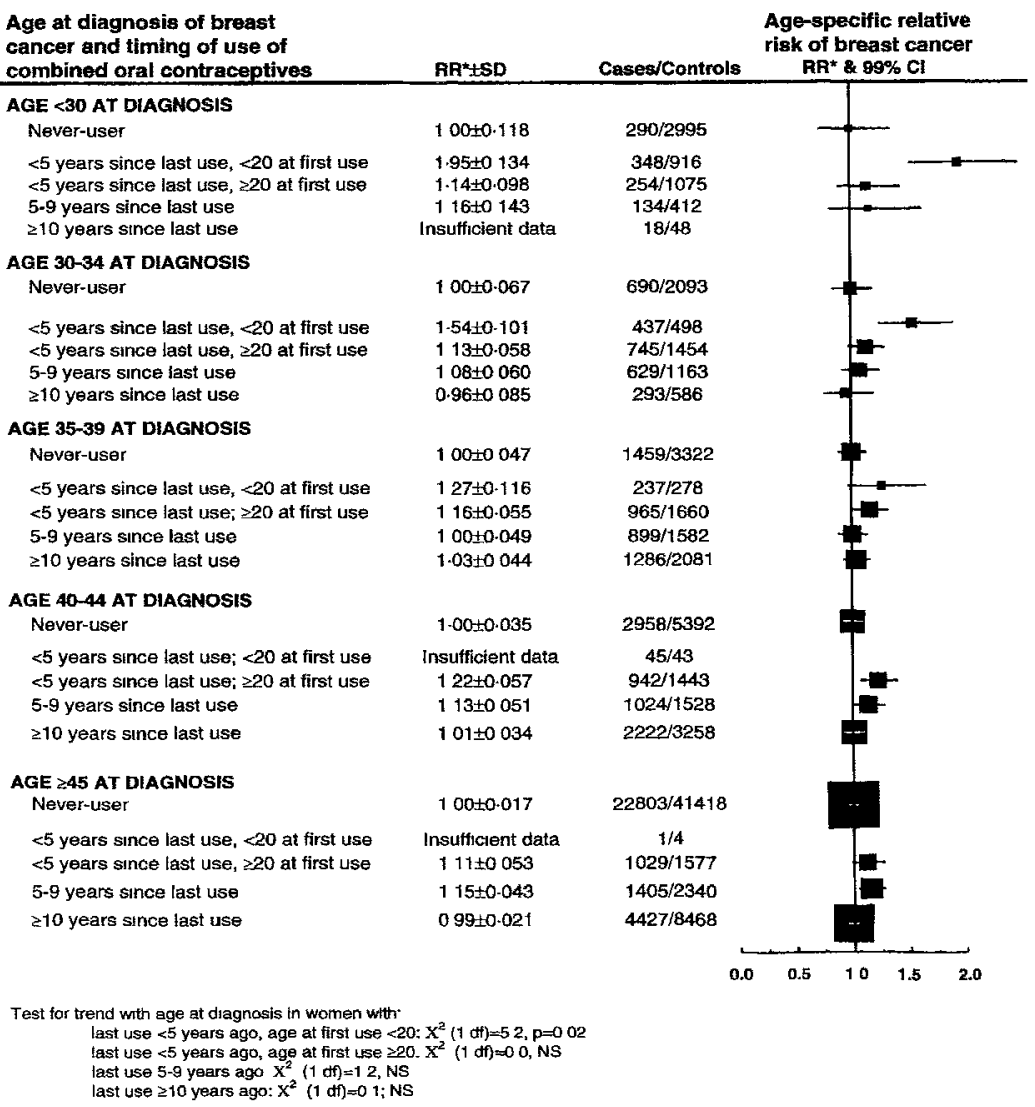

Figure 4: Age-specific relative risk of breast cancer by time since last use of combined oral contraceptives

Format as in figure 2, withın categories of age at diagnosis.

* Relative rısk (given with $99 \% \mathrm{Cl}$ ) relative to never-users, stratified by study, age at diagnosis, parity, and, where appropriate, the age a woman was when her first child was born and the age she was when her risk of conception ceased. 
is drawn as a line; CIs that extend beyond the scale of the plot are indicated by an arrow.

There are two main types of plot. The first type involves a twoway comparison such as ever-use versus never-use, and gives the results separately for all the studies with substantial amounts of statistical information, the remaining studies being included in the relevant other category. In these plots the overall estimate is calculated from the sum of the study-specific values for $\mathrm{O}-\mathrm{E}$ and $\operatorname{var}(\mathrm{O}-\mathrm{E})$. The second type of plot describes the results of categorical analyses involving more than two groups, with variances estimated via the method of floating absolute risks, representing the aggregated results from all relevant studies. Heterogeneity of relative risks and, where appropriate, linear trends are assessed by $\chi^{2}$ tests.

\section{Results}

The 54 studies contributing to these analyses were conducted in 25 countries, mostly in Europe and North America, but Asia, Australasia, Africa, and Latin America were also represented. Together the studies included 53297 women with invasive breast cancer (cases) and 100239 women without breast cancer (controls). The median age at diagnosis of breast cancer was 49 years, and the median year of diagnosis was 1984. At the time of diagnosis, $9 \%$ of women with breast cancer were younger than $35,25 \%$ were $35-44,33 \%$ were $45-54$, and $33 \%$ were 55 and older. Further details of the design of each study and of the women included are given elsewhere. ${ }^{66}$ The analyses here excluded 22 cases and 125 controls who were aged 15 or younger or 90 or older, and 350 cases and 1096 controls with unknown use of oral contraceptives.

\section{Ever-use of combined oral contraceptives}

Overall, $21567(41 \%)$ of the women with breast cancer and $39629(40 \%)$ of the women without breast cancer had ever used combined oral contraceptives. Figure 1 shows for individual studies the numbers of ever-users and never-users and the corresponding relative risk estimates associated with ever-use. The studies are arranged according to study design-prospective studies, casecontrol studies with population controls, and case-control studies with hospital controls. Within the groups the studies are listed in chronological order, according to the median year of diagnosis of breast cancer. The results for studies in which the information content, $\operatorname{var}(\mathrm{O}-\mathrm{E})$, was less than 20.0 are included in the category "other" for the relevant study design. Overall the relative risk of breast cancer in women who had ever used oral contraceptives compared with women who had never used them was slightly above $1 \cdot 0$, and the excess was statistically significant (relative risk 1.07 [SD 0.02 ], 2p=0.00005). There was some evidence of heterogeneity in the results both between the individual studies and between the three types of study design. Ever-use is, however, a crude measure of exposure and represents different patterns of oral contraceptive use in different studies. ${ }^{66}$ Breast cancer risk is therefore considered in relation to various different features of oral contraceptive use that have been thought to be of possible importance.

\section{Timing of exposure}

Breast cancer risk is described in relation to four indices of the timing of exposure to combined oral contraceptivestotal duration of use, age at first use, time since first use, and time since last use. These four indices are highly correlated, ${ }^{66}$ so if breast cancer risk is directly related to

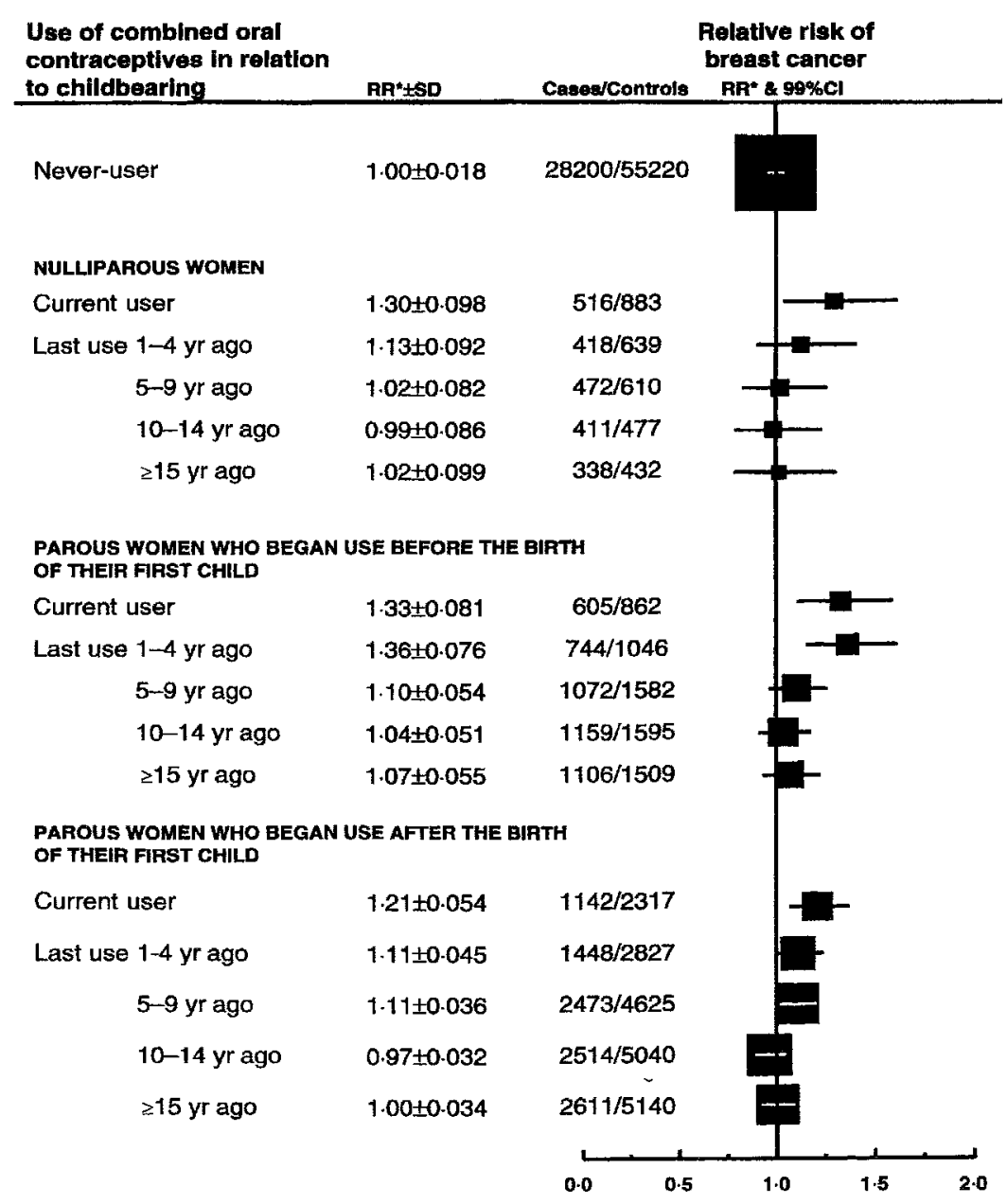

Figure 5: Relative risk of breast cancer by time since last use of combined oral contraceptives and in relation to childbearing history

Format as in figure 2

* Relative risk (given with $99 \% \mathrm{Cl}$ ) relative to never-users, stratified by study, age at diagnosis, parity, and, where appropriate, the age a woman was when her first child was born and the age she was when her risk of conception ceased.

any one, it is likely to be indirectly related to the others. To find out which of the four relations is most direct, the one most strongly related to risk was identified, and then, holding that one factor constant, the other three relations were re-examined. Subsequently breast cancer risk was investigated in relation to other indices of exposure, and the consistency of the main findings was explored in women of different ages and with varying background risks of developing breast cancer.

Total duration of use (figure 2a)-A quarter of everusers were reported to have used oral contraceptives for less than a year and the median total duration of use was 3 years. The relative risk was slightly above 1.0 for each of the five broad categories of use. There was no significant heterogeneity of relative risk of breast cancer between the categories of duration of use, but there was a weak indication of a trend of increasing risk with increasing duration $(\mathrm{p}=0.05)$.

Age at first use (figure 2b)-The age at starting use of combined oral contraceptives ranged from early teens to early $40 \mathrm{~s}$, with a median of $26 ; 14 \%$ of women had begun use before age 20 and $17 \%$ at age 35 or older. ${ }^{66}$ The relative risk was slightly greater than 1.0 for each of the five age groups and was largest for women who started use as teenagers. There was some heterogeneity in the relative risks between the five categories of age at first use $(p=0.01)$ but no significant trend with increasing age at first use. 

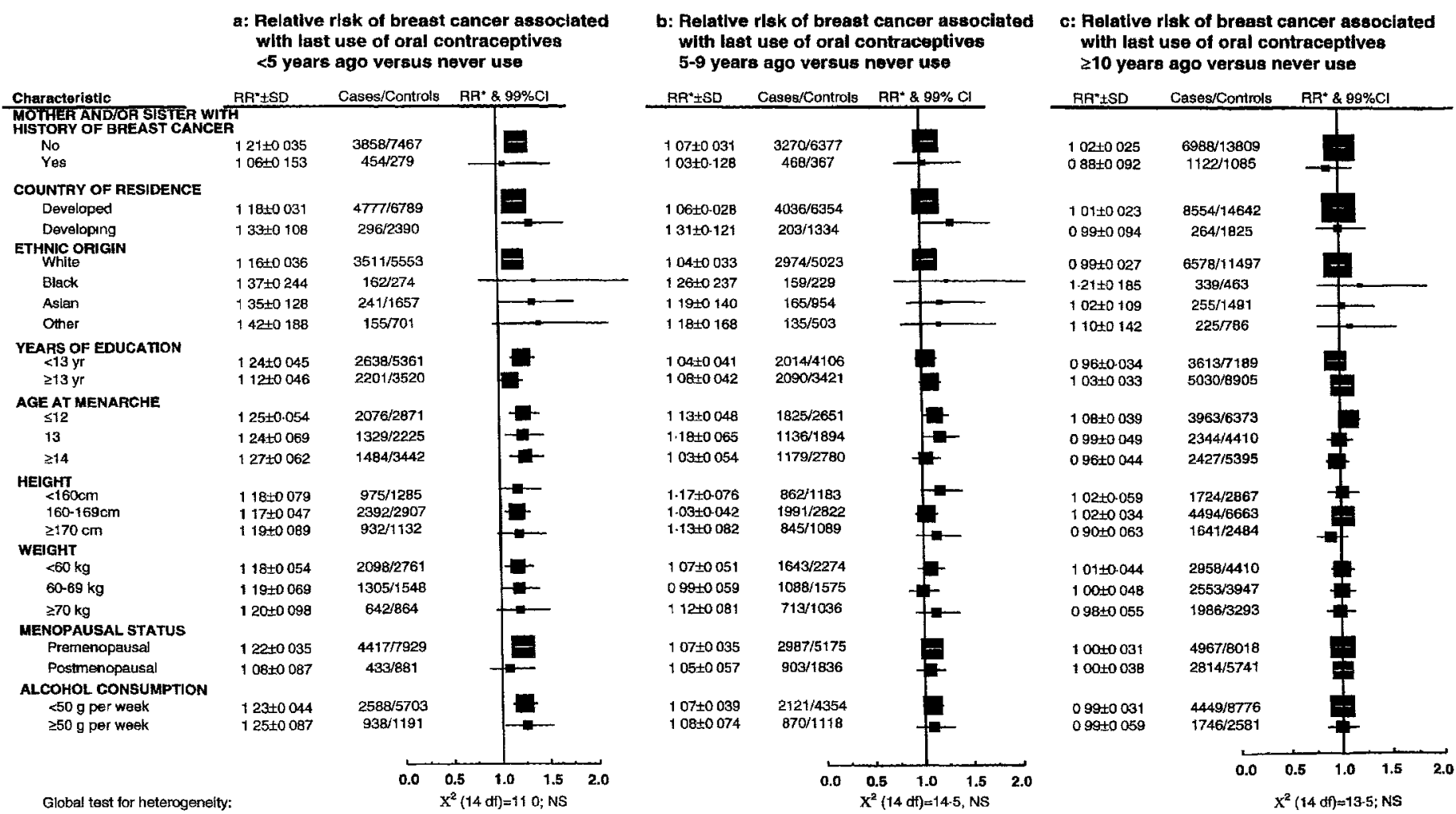

Figure 6: Relative risk of breast cancer by time since last use of combined oral contraceptives among women with different characteristics

Format as in figure 2, except that SDs and CIs are based on conventional variance estimates rather than on those for floating absolute risks. None of the 27 tests for heterogeneity across categories of a particular characteristic is statistically significant.

* Relative risk (given with $99 \% \mathrm{Cl}$ ) relative to never-users, stratified by study, age at diagnosis, parity, and, where appropriate, the age a woman was when her first child was born and the age she was when her risk of conception ceased.

Time since first use (figure 2c)-Most women who had used oral contraceptives had begun use between 10 and 20 years before diagnosis of breast cancer, or pseudodiagnosis in controls (median 16 years). The relative risks were slightly above 1.0 in each 5 -year period of time since first use. There was evidence both of heterogeneity of risk between the five categories $(p=0 \cdot 01)$ and of a trend of decreasing risk with increasing time since first use $(p=0.002)$.

Time since last use (figure $2 d$ )-Current users include women who were taking oral contraceptives at the time of diagnosis (or pseudodiagnosis) or in the preceding 12 months, and about a quarter of ever-users were included in this category. There was evidence of an increased risk of breast cancer being diagnosed in current users (relative risk 1.24 [SD $0 \cdot 04$ ] $2 \mathrm{p}<0.00001$ ) and in women who stopped use $1-4$ years previously $(1 \cdot 16$ [0.04], $2 p=0.00001$ ), with some evidence of an increased risk 5-9 years after stopping $(1.07[0.03], 2 p=0.009)$. For women who stopped use 10 or more years ago, the relative risk did not differ significantly from $1.0(1.01$ [0.02], NS). Virtually all the information on use that ceased more than 10 years ago relates to use that ceased between 10 and 20 years ago. There was substantial heterogeneity in the relative risks between the five categories of time since last use $(p<0.00001)$ and a strong trend of decreasing risk with time since last use $(\mathrm{p}<0.00001)$.

Each of the four $\chi^{2}$ tests for heterogeneity shown in figure 2 is on four degrees of freedom and each of the tests for trend is on one degree of freedom, so the $\chi^{2}$ values can be compared directly. On the basis of both types of test, of the four factors examined, time since last use (figure $2 \mathrm{~d}$ ) is most strongly related to breast cancer risk (for heterogeneity, $\chi^{2}=41 \cdot 5$, compared with $8 \cdot 0,13 \cdot 4$, and
13.4; and for trend, $\chi^{2}=31 \cdot 7$, compared with $3 \cdot 9,0 \cdot 2$, and $9 \cdot 6)$.

The increased risk associated with current and recent use and the absence of an increase in risk associated with use that ceased 10 or more years ago remained within each of the categories of the other three indices of exposure (figure 3). Furthermore, when the results according to time since last use were examined in detail to find out whether adjustment for other possible confounders, such as family history of breast cancer, age at menarche, or weight, might modify the magnitudes of the relative risks in figure $2 \mathrm{~d}$, none was found to do so. ${ }^{6}$

\section{Residual effects of other indices of exposure, given time} since last use

The residual effects of the three other main indices of exposure within each time since last use category are shown in figure 3. No residual effects were evident for total duration of use or for time since first use: none of the tests for trend or heterogeneity was significant for either of these factors within each of the five categories of time since last use. Since breast cancer risk is more strongly related to recent than to past use, it is possible that total duration of use might not be relevant for women who used oral contraceptives intermittently, with long breaks inbetween. However, analyses restricted to women whose entire use of oral contraceptives was interrupted by less than 24 months (pregnancies excluded) also showed no significant trend in breast cancer risk with duration of use, even when use was, in this sense, virtually continuous. ${ }^{\circ}$ Also, when durations of use were calculated, restricted to the time when women were nulliparous, there was no relation between duration of use while nulliparous and breast cancer risk. ${ }^{66}$ 


\section{a: Relative risk of breast cancer in women whose last use of combined oral contraceptives was $<5$ years ago}

\section{b: Relative risk of breast cancer in women whose last use of combined oral contraceptives was $\geq 5$ years ago}
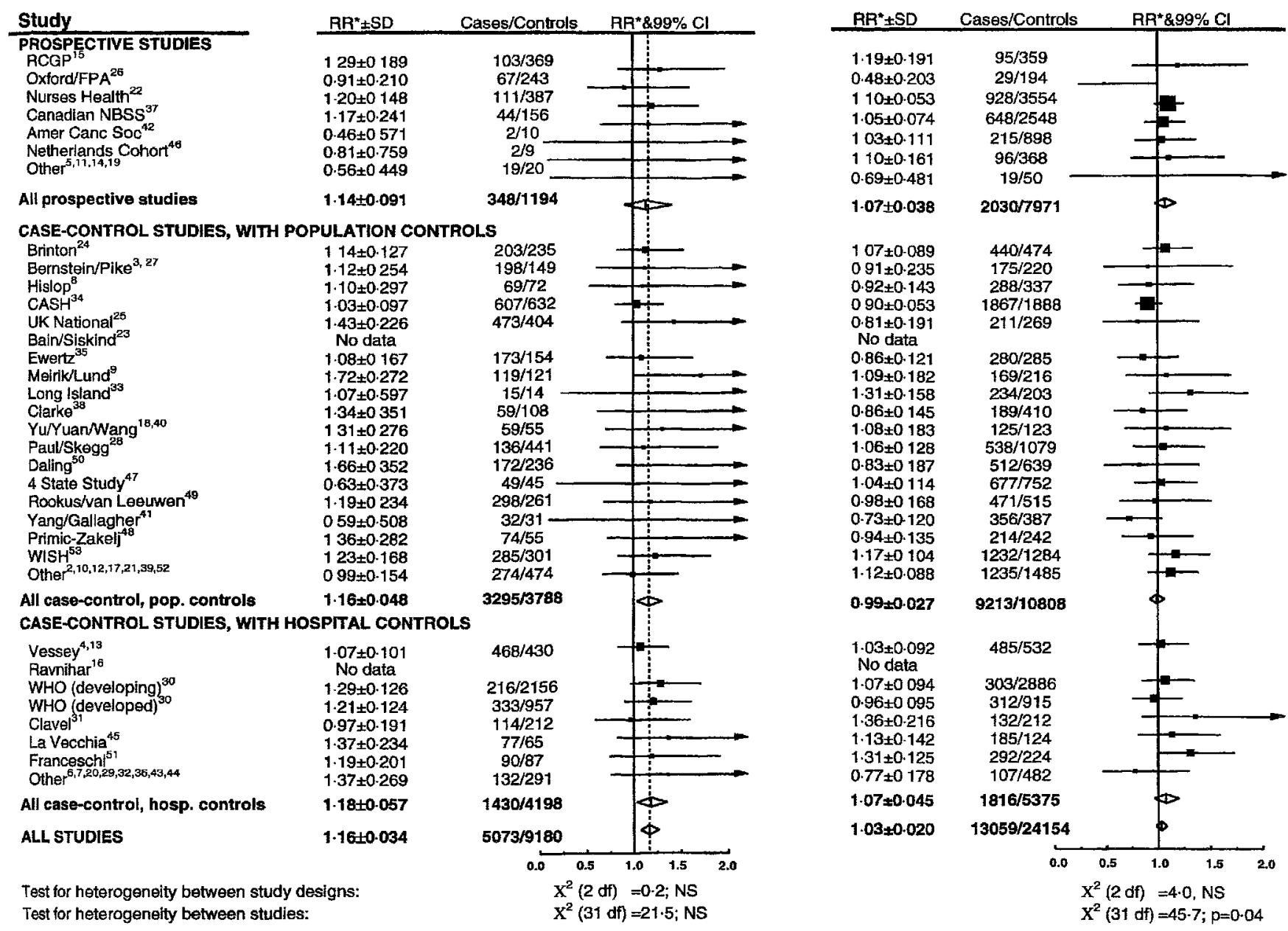

Figure 7: Relative risk of breast cancer in recent and past users of combined oral contraceptives

Format as in figure 1 . Where the upper $\mathrm{Cl}$ is greater than $2 \cdot 0$, this is indicated by an arrow.

*Relative risk (given with $99 \% \mathrm{Cl}$ ) relative to never-users, stratified by study, age at diagnosis, parity, and, where appropriate, the age a woman was when her first child was born and the age she was when her risk of conception ceased.

There was, however, significant heterogeneity of risk by age at first use in current users $(p=0.005)$ and in women who stopped use 1-4 years ago $(p=0 \cdot 006)$, with current and recent users who began use before age 20 having significantly higher relative risks than women who began at older ages (figure $3 b$ ). By contrast, among women whose use ceased 5 or more years ago, the relative risks were not materially affected by the age when use began. For women who began use before age 20 and stopped use more than 15 years ago the relative risk fell from $1 \cdot 14$ to 1.01 when ever-users were taken to be women with a duration of use of greater than a year, suggesting that there may be differential recall between cases and controls of brief use at early ages that ceased long ago. ${ }^{66}$

The effects of other indices of the timing of exposure were examined, including age at last use, year of first use, and year of last use of oral contraceptives; however, no other factor appeared to have much effect on breast cancer risk once account had been taken of time since last use and age at first use. ${ }^{66}$

\section{Consistency of effect of time since last use}

Although it is of interest to examine how consistent the main findings appear to be, it should be borne in mind that analyses restricted to particular subgroups may by chance alone yield misleadingly irregular patterns.

Age at diagnosis The pattern of an increased relative risk of breast cancer in recent users (ie, women whose last use was within the previous 5 years), with no increased risk 10 or more years after cessation of use, was found consistently at all ages (figure 4). Furthermore, for recent users who began use after age 20, and for past users who ceased use 5-9 or 10 or more years previously, the relative risks did not vary significantly with age at diagnosis. For women who began use before age 20 the relative risk associated with current or recent use, although consistently higher than for women who began use at older ages, tended to decline with increasing age at diagnosis. Within specific age groups, there was no statistically significant trend with duration of use, once time since last use and age at first use had been taken into account. ${ }^{66}$

Women with different background risks of breast cancer A woman's reproductive history affects both her use of oral contraceptives and her risk of breast cancer. ${ }^{60}$ Although stratification for various features of reproductive history should avoid material confounding due to those variables, it is of interest to examine whether the results relating to oral contraceptive use are consistent for women with different childbearing patterns. Nulliparous women are a special group in that there is no opportunity for the effects of oral contraceptive use to be modified or confounded by childbearing. In nulliparous women the pattern of risk with respect to time since last use is similar to that found for all women (figure 5). Moreover, among parous women the pattern of risk is similar irrespective of whether oral contraceptive use began before or after the 


\begin{tabular}{|c|c|c|c|}
\hline Tumour spread & $\mathrm{RR}^{*} \pm \mathrm{SD}$ & $\begin{array}{c}\text { Combined oral } \\
\text { contraceptlve use } \\
\text { EverNover }\end{array}$ & RR० $\& 99 \% \mathrm{Cl}$ \\
\hline $\begin{array}{l}\text { Localised to the } \\
\text { breast }\end{array}$ & $1.00 \pm 0.027$ & $6912 / 5628$ & \\
\hline $\begin{array}{l}\text { Spread to lymph } \\
\text { nodes only }\end{array}$ & $0.89 \pm 0.029$ & $4535 / 4152$ & \\
\hline Distant metastases & $0.70 \pm 0.106$ & $243 / 419$ & \\
\hline
\end{tabular}

Test for heterogeneity by extent of tumour spread: $X^{2}(2 \mathrm{df})=13 \cdot 2 ; p=0.001$

Figure 8: Analyses relating extent of tumour spread among women with breast cancer to ever-use of combined oral contraceptives

Format as in figure 2. The reference group is women whose cancers are localised to the breast. Relative risk estimates represent the probability that women whose cancers have spread beyond the breast are everusers compared with the probability that women whose cancers are localised to the breast are ever-users.

* Relative risk (given with $99 \% \mathrm{Cl}$ ) relative to never-users, stratified by study, age at diagnosis, parity, and, where appropriate, the age a woman was when her first child was born and the age she was when her risk of conception ceased.

birth of the first child (figure 5). Similar patterns of risk with respect to time since last use of oral contraceptives were found for women of different parity and for women who had their first child at different ages. ${ }^{6}{ }^{6}$ The relations according to time since last use of oral contraceptives were similar for women with and women without a family history of breast cancer, for women from different countries and ethnic groups, for women of different heights and weights, and in premenopausal and postmenopausal women (figure 6). None of the 27 comparisons made in figure 6 was statistically significant. For each time since last use category $(<5,5-9, \geqslant 10)$ an overall test of heterogeneity was calculated by summing the nine respective individual $\chi^{2}$ values to give an overall $\chi^{2}$ statistic on $14 \mathrm{df}$. The value of each of these statistics was consistent with what would be expected if there were no heterogeneity in the relative risks by any of the characteristics considered. Separate analyses for recent users who began use before and after age 20 identified no additional variation in risk between these subgroups. ${ }^{66}$

Different studies A slightly increased relative risk of breast cancer among recent users of combined oral contraceptives was found consistently between the three types of study design and between studies, although in most individual studies the excess was not statistically significant (figure 7a). For women who stopped use more than 5 years ago there was also no evidence of heterogeneity between the study designs, and only weak heterogeneity between the individual studies (figure $7 \mathrm{~b}$ ).

\section{Tumour spread}

The breast cancers diagnosed in women who had used combined oral contraceptives were significantly less advanced clinically than those diagnosed in never-users. Tumours in ever-users were less likely to have spread to axillary lymph nodes (relative risk 0.89 [SD 0.04 ],

\begin{tabular}{|c|c|c|c|c|}
\hline Study & $\mathrm{RA}^{*} \pm \mathrm{SD}$ & $\begin{array}{c}\text { Combined ora } \\
\text { Ever } \\
\text { spread/localised }\end{array}$ & $\begin{array}{c}\text { Never } \\
\text { spreadhocalised }\end{array}$ & $\begin{array}{l}\text { Risk of spread } \\
\text { compared to } \\
\text { localised cancer } \\
\mathrm{RA}^{*} \& 99 \% \mathrm{Cl}\end{array}$ \\
\hline $\begin{array}{l}\text { PROSPECTIVE STUDIES } \\
\text { Nurses Health } \\
\text { Canadian NBSS }^{37}\end{array}$ & $\begin{array}{l}0.84 \pm 0.091 \\
0.85 \pm 0.136\end{array}$ & $\begin{array}{l}385 / 623 \\
245 / 496\end{array}$ & $\begin{array}{l}605 / 915 \\
206 / 388\end{array}$ & - \\
\hline All prospectlve studies & $0.85 \pm 0.075$ & $630 / 1119$ & $811 / 1303$ & \\
\hline $\begin{array}{l}\text { CASE-CONTROL STUDIES } \\
\text { Hislop }\end{array}$ & $\begin{array}{l}\text { POPULATIO } \\
115 \pm 0.525\end{array}$ & $\begin{array}{r}\text { CONTROLS } \\
36 / 186\end{array}$ & $54 / 235$ & \\
\hline $\mathrm{CASH}^{34}$ & $0.97 \pm 0.072$ & $1236 / 1545$ & $851 / 1019$ & \\
\hline UK National ${ }^{25}$ & $0.55 \pm 0.235$ & $192 / 405$ & $27 / 40$ & \\
\hline Bain/Siskind ${ }^{23}$ & $1.68 \pm 0.444$ & $95 / 85$ & $150 / 162$ & \\
\hline Ewertz $^{35}$ & $0.81 \pm 0.165$ & $133 / 279$ & $375 / 542$ & \\
\hline Long $\mid$ s|and ${ }^{33}$ & $1.06 \pm 0.231$ & $112 / 140$ & $363 / 489$ & \\
\hline Daling ${ }^{50}$ & $0.61 \pm 0.249$ & $283 / 397$ & $30 / 30$ & \\
\hline Rookus/van Leeuwen ${ }^{4 \theta}$ & $0.97+0.247$ & $343 / 414$ & $72 / 61$ & \\
\hline Primic-Zakelj ${ }^{48}$ & $0.69 \pm 0.201$ & $214 / 71$ & $260 / 58$ & i \\
\hline WISH ${ }^{53}$ & $1.12 \pm 0.157$ & $652 / 851$ & $133 / 193$ & \\
\hline Other $r^{2,21,52}$ & $0.82 \pm 0.139$ & $400 / 787$ & $318 / 342$ & \\
\hline $\begin{array}{l}\text { All cass-control studies, with } \\
\text { population controls }\end{array}$ & $0.93 \pm 0.049$ & $3696 / 5160$ & $2633 / 3171$ & \\
\hline $\begin{array}{l}\text { CASE-CONTROL STUDIES } \\
\text { VESSEY }\end{array}$ & $\begin{array}{l}\text { HOSPITAL } \\
0.60 \pm 0.164\end{array}$ & $\begin{array}{l}\text { ONTROLS } \\
64 / 189\end{array}$ & $146 / 271$ & \\
\hline Ravnihar ${ }^{16}$ & $0.75+0.220$ & $55 / 98$ & $148 / 201$ & \\
\hline WHO ${ }^{30}$ & $0.61 \pm 0.302$ & $160 / 87$ & $331 / 225$ & \\
\hline Clavel $^{3 t}$ & $0.67 \pm 0.237$ & $74 / 162$ & $90 / 144$ & \\
\hline Other $r^{20,32,43}$ & $0.99 \pm 0.381$ & $99 / 97$ & $412 / 313$ & \\
\hline $\begin{array}{l}\text { All case-control studies, with } \\
\text { haspital controls }\end{array}$ & $0.68 \pm 0.104$ & $452 / 633$ & $1127 / 1154$ & $<1$ \\
\hline ALL STUDIES & $0.88 \pm 0.038$ & $4778 / 6912$ & $4571 / 5628$ & $>$ \\
\hline
\end{tabular}

Test for heterogeneity between study designs: $X^{2}$ (2 df)=5.6; NS

Test for heterogeneity between study dssigns: $X^{2}(2 \mathrm{df})=5.6 ;$
Test for heterogeneity between studies: $X^{2}(17 \mathrm{df})=19.8 ;$ NS

Figure 9: Extent of tumour spread among women with breast cancer in ever-users compared with never-users of combined oral contraceptives

Format as in figure 1.

*Relatıve rısk (given with $99 \% \mathrm{CI}$ ) relatıve to never-users, stratified by study, age at diagnosis, parity, and, where appropriate, the age a woman was when her first child was born and the age she was when her risk of conception ceased. 


\section{a: Relative risk of cancer localised to the breast by time since last use of combined oral contraceptives}

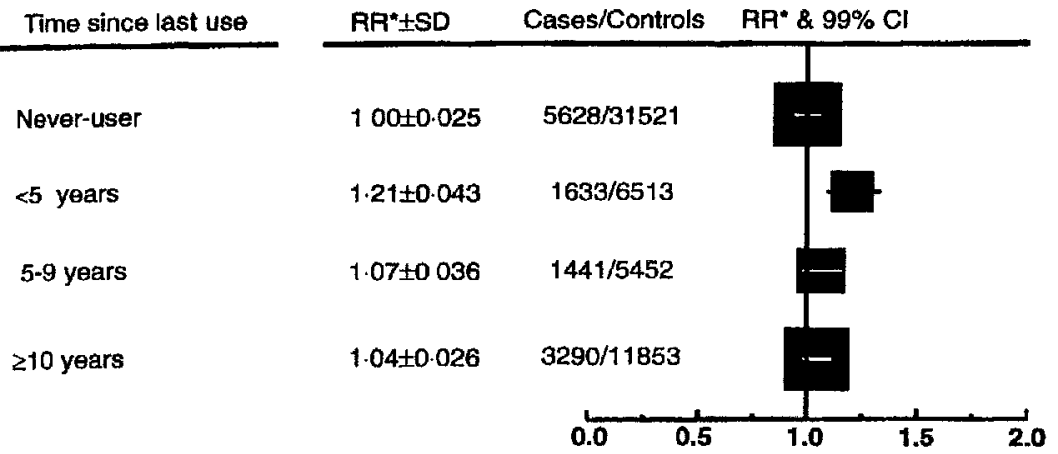

b: Relative risk of cancer spread beyond

the breast by time since last use of

combined oral contraceptives

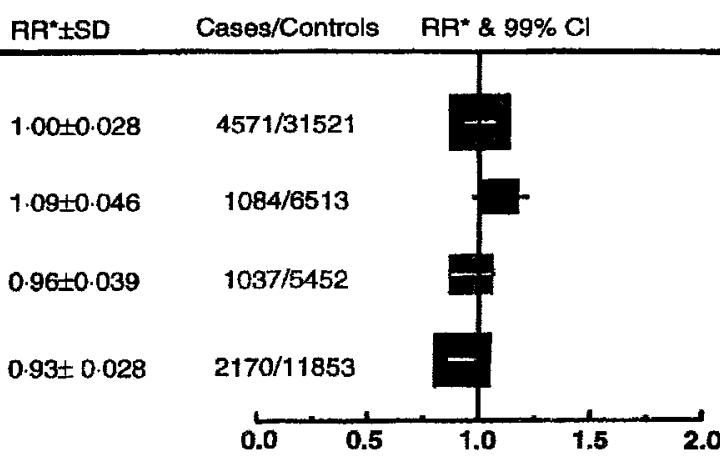

Figure 10: Relative risk of breast cancer by time since last use of combined oral contraceptives according to extent of tumour spread

Format as in figure 2.

* Relative risk (given with $99 \% \mathrm{CI}$ ) relative to never-users, stratified by study, age at diagnosis, parity, and, where

appropriate, the age a woman was when her first child was born and the age she was when her risk of conception ceased.

$2 \mathrm{p}=0.006)$ or to more distant sites $(0 \cdot 70[0 \cdot 11]$ $2 p=0 \cdot 006$ ) than to be localised to the breast (figure 8 ). This finding of a relative deficit of tumours that had spread beyond the breast in ever-users did not differ significantly across the studies with information on tumour spread, nor according to study design (figure 9).

Both for women with localised tumours and for women with more extensive disease, the relation with recency of oral contraceptive use was similar to that found for all women, the relative risks declining significantly with time since last use (figure 10: $\chi^{2}$ for trend, $p=0 \cdot 004$, for each). The relative risk of localised disease was significantly increased in recent users and remained slightly increased 5-9 and 10 or more years after cessation of use (figure 10a). By contrast, the relative risk of cancer that had spread beyond the breast was slightly and non-significantly raised in recent users, and, if anything, was reduced 5-9 and 10 or more years after cessation of use (figure 10b). These results suggest that much of the excess risk of breast cancer in recent users is due to an excess of localised tumours. The magnitude of the relative deficit of more extensive disease did not vary significantly with time since last use of oral contraceptives (test for heterogeneity $\chi^{2}=3 \cdot 1, \mathrm{df}=2, \mathrm{NS}$; overall relative risk 0.88 [SD $0 \cdot 04$ ], $2 p=0.002$ ) and the relative deficit was still evident 10 or more years after use (relative risk 0.85 [SD 0.05 ], $2 \mathrm{p}=0.001)$

\section{Constituents of hormonal contraceptives}

Among women for whom information was available about the particular combined oral contraceptive preparations used, there was no significant variation in the relative risks associated with use of specific types of oestrogen or of progestagen, either in recent or in past users. ${ }^{66}$ When the preparations were grouped into three broad categories according to hormone dose there was, if anything, a decrease in the risk of breast cancer with increasing dose

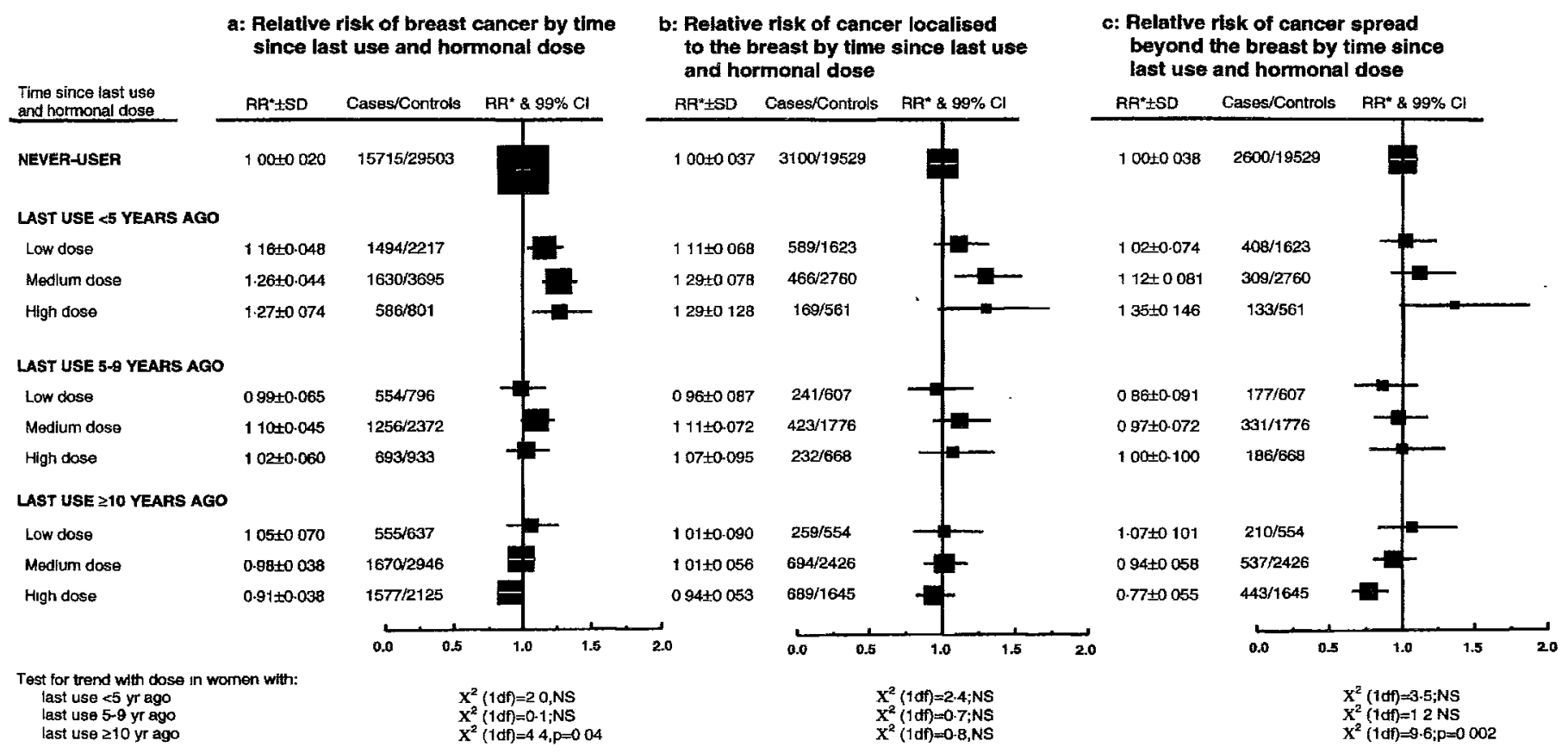

Figure 11: Relative risk of breast cancer by time since last use and hormonal dose in combined oral contraceptive last used

Format as in figure 2. Results are given separately for all cancers and for cancers that were localised to the breast and that had spread beyond the breast. Not all studies with information about hormonal dose also provided information about tumour spread.

* Relative risk (given with $99 \% \mathrm{Cl}$ ) relative to never-users, stratified by study, age at diagnosis, parity, and, where appropriate, the age a woman was when her first child was born and the age she was when her risk of conception ceased. 
among women who had stopped use 10 or more years before, largely due to a reduction in breast cancer risk among those who had used the highest-dose preparations (figure 11a). There were no significant trends with duration of use among women who had used low-dose, medium-dose, or high-dose preparations. ${ }^{66}$

The pattern of risk in relation to hormone dose was also examined according to the extent of tumour spread. For women whose tumours had spread beyond the breast there was a significant decrease in risk with increasing dose in women who stopped use more than 10 years previously (figure 11c) but for women with localised disease the patterns were less pronounced and not statistically significant (figure $11 \mathrm{~b}$ ). These results relate to dose in the preparation last used, but broadly similar results were obtained for dose in the preparation first used and that used for the longest time. ${ }^{66}$

Hormonal contraceptives containing progestagens only have not been widely used: oral progestagen-only preparations had been used by only $0.8 \%$ of the study population and injectable progestagens by only $1.5 \% .^{66}$ The amount of information available was limited, but the results were broadly similar to those found for combined oral contraceptives, with some evidence of an increase in risk for use in the previous 5 years (relative risk $1 \cdot 17$ $[S D=0.09], \quad p=0.06$, for oral preparations; 1.17 $[S D=0 \cdot 13], N S$, for injectable progestagens) but no evidence of an increase in risk 10 or more years after stopping use $(0 \cdot 99[\mathrm{SD}=0 \cdot 13], \mathrm{NS}$, for oral preparations; $0.94[\mathrm{SD}=0.13], \mathrm{NS}$, for injectable preparations). There were no apparent residual effects of duration of use or age at first use, but the numbers are too small to exclude such effects with any certainty. ${ }^{60}$

\section{Discussion}

This review of 54 studies, conducted in 25 countries, provides strong evidence for two main conclusions. First, while women are taking combined oral contraceptives and in the 10 years after they stop there is a small but definite increase in the risk of having breast cancer diagnosed. Second, this excess risk does not persist and there is no evidence of an increased risk of breast cancer 10 or more years after cessation of use (figure 12). Furthermore, the cancers diagnosed in women who have ever used oral contraceptives are less likely to have spread beyond the breast than those diagnosed in women who have never used oral contraceptives (figures 8-10). Before we consider the implications of these findings, their reliability and consistency are discussed.

\section{Combining results from many studies}

Because the 54 studies included here were of varied design and were carried out among women with different baseline risks of breast cancer in different settings, the relative risks associated with the use of oral contraceptives might have been expected to differ substantially between the study designs and between the individual studies. However, after recency of use was taken into account there was no pronounced variability between studies or study designs (figure 7) or between women with different background risks of breast cancer (figures 5 and 6).

Combining results from many studies has the obvious advantage of reducing random errors. Furthermore, because chance alone would make some studies suggest one conclusion and others suggest another conclusion,

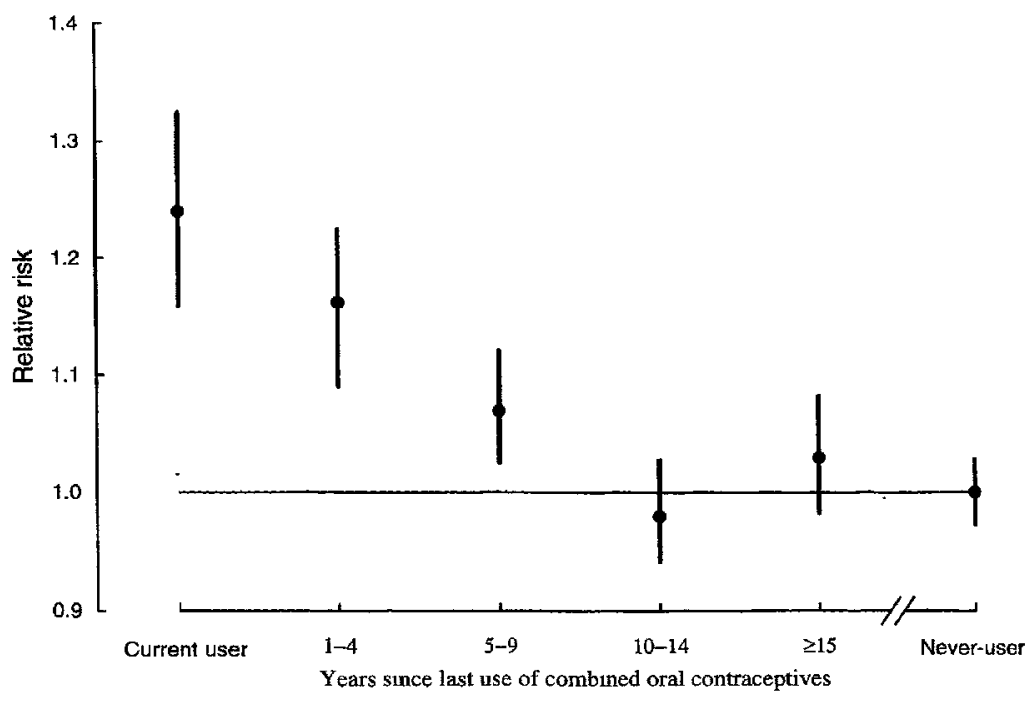

Figure 12: Relative risk of breast cancer by time since last use of combined oral contraceptives

Relative risk (given with $95 \% \mathrm{Cl}$ ) relative to never-users, stratified by study, age at diagnosis, parity, age at first birth, and age at which risk of conception ceased.

systematic analysis of the worldwide evidence reduces biases that can be produced by undue emphasis on particular studies with extreme results. Although the 54 studies included here were of varied size, no single study was so large as to dominate the overall results.

The data presented here represent about $90 \%$ of the worldwide epidemiological evidence on breast cancer risk and use of hormonal contraceptives. What is known about the 12 studies for which data were not included suggests that their results would have been consistent with the main findings. The pooled estimate of the relative risk of everuse of oral contraceptives compared with never-use from those studies ${ }^{51-65}$ was 1.07 (SD 0.04), which is identical to the estimate of 1.07 found for the data included (figure 1). Five of these studies ${ }^{54,57,59,62,65}$ published data on recent use of oral contraceptives, and the pooled estimate of the relative risk associated with current use or recent use (usually representing use in the last 3 years) was $1 \cdot 16$ (SD $0 \cdot 11$ ) which again resembles our estimate of 1.16 for recent users (figure $7 \mathrm{a}$ ). No omitted study reported an increase in breast cancer many years after cessation of oral contraceptive use-in fact, seven ${ }^{54-59,63}$ were among the earliest studies ever done, and so could not have produced much evidence of any long-term effect to modify the findings reported here for past users. The main results are therefore unlikely to be materially affected by the omission of about $10 \%$ of the epidemiological evidence.

\section{Bias, confounding, and chance}

As well as the biases that could be caused by undue emphasis on particular studies, selective emphasis on particular subgroups can also introduce bias. Despite the large amount of information available, some untrustworthy irregularities inevitably emerge when data are subdivided in many ways. Nevertheless, it is necessary to divide the data into many subgroups, as has been done here, to examine which patterns of use are associated with risk, and how that risk varies with age, family history, and so on. This report contains some 400 relative risk estimates and their respective confidence intervals. A few apparently heterogeneous findings are observed but it is important to bear in mind that at least part of this apparent variation in risk between subgroups is likely to be due to chance. 
Biases can also be introduced if there is differential reporting of oral contraceptive use by cases and controls. The reporting of very short durations of use is a potential source of bias, because a quarter of the ever-users were reported as having used oral contraceptives for less than a year and the proportion of such users varied substantially from one study to another. ${ }^{66}$ Even a slight tendency for short-duration use to be reported in different ways by cases and controls could bias the results; to assess the potential relevance of this bias, the main analyses were repeated with ever-users defined as women with durations of use of more than a year. ${ }^{66}$ The main conclusions about the relation of breast cancer with respect to time since last use were not altered. There was, however, some suggestion that there may be slight differences in the reporting of brief use at young ages that ceased long ago. Another potential bias is that women who have used oral contraceptives may have their cancer detected earlier than women who have never used oral contraceptives (discussed later).

To minimise the potential for confounding, all analyses were simultaneously stratified for study, age at diagnosis in single years, parity, and, where appropriate, the age a woman was when her first child was born, and the age when her risk of conception ceased. This fine stratification means that no direct comparisons were made between women in one study and women in another and that the contraceptive history of a woman with breast cancer is compared only with that of control women in the same study who were exactly the same age as her and had a similar reproductive history. Although the stratification is fine enough to avoid any material confounding by these factors, it was not excessively fine, since the standard deviations of the main risk estimates are still small. Adjustment for other factors did not alter the associations described here. ${ }^{66}$

Since the various measures of the timing of exposure to oral contraceptives are highly correlated, failure to stratify by time since last use and age at first use can confound the associations with other related exposures. ${ }^{66}$ For example, duration of oral contraceptive use in young women is highly correlated with time since last use and age at first use, and analyses that do not stratify by those factors can produce apparent associations between breast cancer risk and duration of use.

\section{Excess risk in recent users}

The increased risk of breast cancer being diagnosed among current users and among women whose use ceased 1-4 years previously is each based on large numbers and is highly statistically significant. These findings were seen consistently between studies, although few studies showed a significant excess in their own right (figure $7 \mathrm{a}$ ). The relative risk declined with time after cessation of use and was still slightly increased 5-9 years after cessation of use (figure 12). The excess risk in recent users was largely associated with tumours localised to the breast (figure 10).

Few factors appeared to modify the relative risks associated with recent use of oral contraceptives, despite the large number of possibilities considered. ${ }^{66}$ For example, there was no strong evidence of variation in risk with duration of oral contraceptive use, or with respect to family history of breast cancer, ethnic origin, age at menarche, height, weight, menopausal status, or alcohol use. The only factor identified that had much effect on the relative risk associated with recent use of oral contraceptives was age at first use (figure $3 b$ ). For recent users the relative risks were greater for those who began before age 20 than for those who began at later ages (figure $3 \mathrm{~b}$ ) and tended to decline with increasing age at diagnosis (figure 4 ).

Overall, the risk of breast cancer in recent users is not significantly related to the dose or type of hormone within the hormonal contraceptive used. ${ }^{66}$ The limited information available for hormonal contraceptives containing progestagens alone suggests that use of oral or injectable progestagen-only preparations might also involve a small increase in breast cancer being diagnosed in recent users.

\section{No adverse effect in the long term}

There is no evidence of an excess risk of breast cancer 10 or more years after cessation of use overall (relative risk 1.01 [SD 0.02]). The lack of an increased risk 10 or more years after stopping is seen fairly consistently in individual studies and in most subgroups of women. The cancers diagnosed 10 or more years after cessation of use are, however, slightly less likely to have spread beyond the breast than the cancers diagnosed in never-users (figure 10).

Although the absence of an increase in breast cancer risk 10 or more years after cessation of oral contraceptive use is reliably established, the available information is still somewhat limited. Oral contraceptives have been widely used only since the 1960 s and most of the cancers included in these analyses were diagnosed during the 1980 s. Thus there is still little information beyond 20 years after cessation of use. Moreover, most women who stopped use 10 or more years ago had used oral contraceptives only for short periods (figure $3 \mathrm{a}$ ) and tended to have used medium-dose or high-dose preparations (figure 11).

\section{Possible explanations of findings}

The relations observed here between cancer risk and exposure are unusual, since the risk increases soon after first exposure, does not increase with duration of exposure, and returns to normal 10 years after cessation of exposure. Such a pattern seems incompatible with a genotoxic effect. An increased risk in recent users is, perhaps, compatible with the classic concept of the promotion of tumours that have already been initiated. The deficits in risk seen in certain groups 10 or more years after cessation of exposure, if confirmed, might be indicative of analogous effects of hormonal contraceptives and of childbearing on breast cancer risk.

The finding that the breast cancers in women who had used oral contraceptives were less advanced clinically than those in never-users raises the possibility that users of oral contraceptives may have had their cancers diagnosed earlier in the development of the disease than would otherwise have happened. If this were so, the implication from these data is that women who have used oral contraceptives continue to have their cancers diagnosed earlier than never-users even many years after use ceases because the relative excess of localised tumours is similar in current and past users and does not vary significantly with time since last use. ${ }^{\circ 0}$ Alternatively, oral contraceptives might affect the rate of growth of tumours and their tendency to metastasise. It is not possible to infer from 


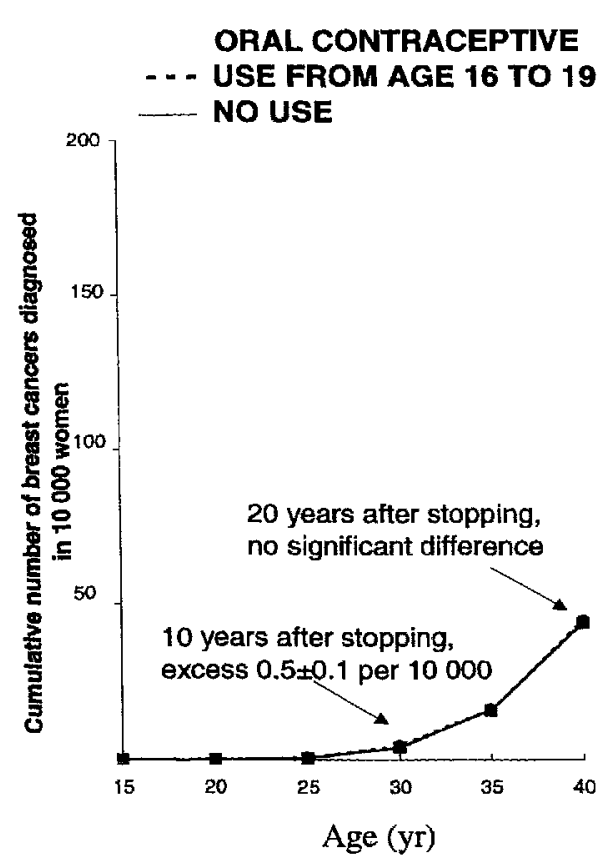

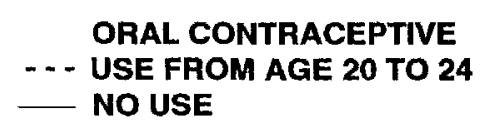

NO USE

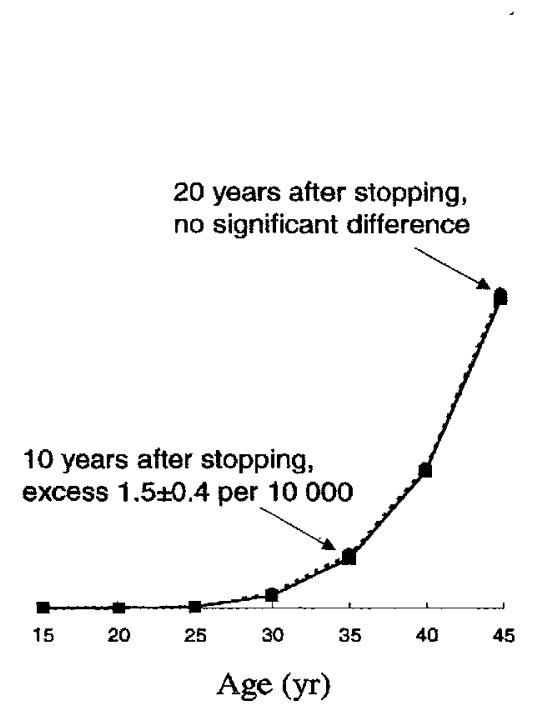

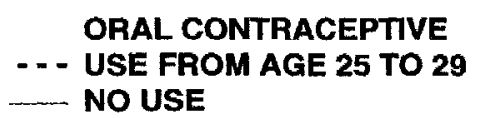

NO USE

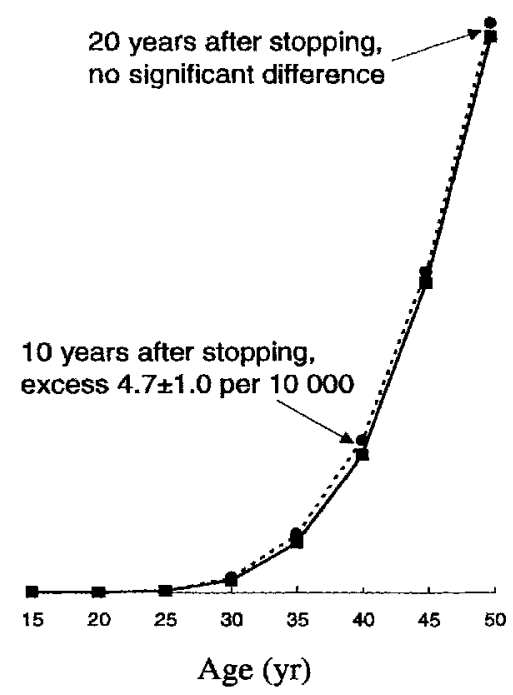

Figure 13: Estimated cumulative number of breast cancers diagnosed in never-users and in women who used oral contraceptives at various ages

Estimated numbers for 10000 women in Europe or North America; details of calculations are given elsewhere. ${ }^{66}$ Note: the estimated numbers for ever-users and never-users are so similar in some age ranges that they overlap almost entirely.

these data whether the patterns of risk observed are due to an earlier diagnosis of breast cancer in ever-users, the biological effects of hormonal contraceptives, or a combination of both factors. Further information is needed on whether women who have used oral contraceptives are more likely to have their cancers detected earlier, how long the deficit of advanced disease persists, its relation to hormone dose, and whether there is differential survival in ever-users and never-users.

There is no clear explanation for the finding that the relative risk associated with current use or use that ceased in the previous 5 years is higher for women who began use before age 20 than after that age. This finding could reflect a comparatively greater effect of the artificial preparations before adult hormone secretion patterns are fully established. Alternatively, it could be partly due to differential reporting of use at young ages by cases and controls, chance, or a combination of reasons. The available data for use beginning before age 20 indicate that there is no substantial increase of breast cancer risk in this subgroup more than 5 years after cessation of use, but virtually all the existing information relates to women younger than 45 . In the next decade women who began use as teenagers will reach their late 40 s and early $50 \mathrm{~s}$, when breast cancer is more common. When the new data on the long-term effects of early use become available it will be necessary to re-examine the worldwide evidence.

\section{Calculated numbers of breast cancers diagnosed in ever-users compared with never-users}

Even though it is not possible to infer from these data whether the findings described here are due to the earlier diagnosis of breast cancer among ever-users, the biological effects of hormonal contraceptives, or a combination of reasons, the approximate number of cancers that would be diagnosed in women who have used oral contraceptives can be calculated. Combining the estimates of relative risk by time since last use suggested by these analyses with incidence rates of breast cancer in various populations, calculations were made of the cumulative number of breast cancers diagnosed in women who had used oral contraceptives at various ages for various durations. ${ }^{66}$ Figure 13 shows, as an example, the calculated cumulative numbers of cancers diagnosed in 10000 women in Europe or North America who used oral contraceptives from age 16 to 19 , from age 20 to 24 , and from age 25 to 29 , compared with women who had never used them. There is a small excess in the estimated number of cancers diagnosed in the period from starting oral contraceptive use up to 10 years after stopping, but by 20 years after

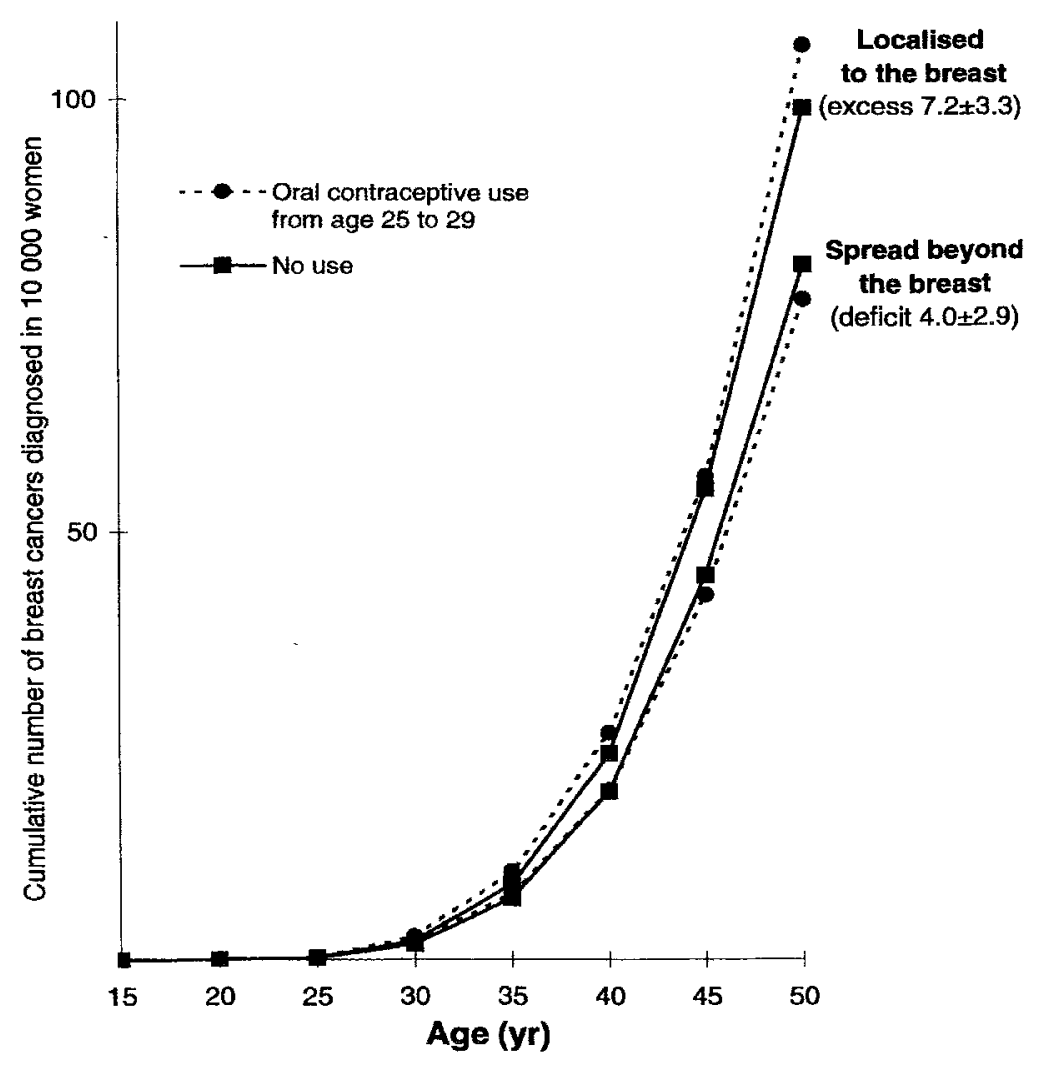

Figure 14: Estimated cumulative number of breast cancers diagnosed in never-users and in women who used oral contraceptives from age 25 to 29 , according to extent of tumour spread

Estımated numbers for 10000 women in Europe or North America; details of calculations are given elsewhere. ${ }^{66}$ 
stopping there is no significant difference between everusers and never-users in the cumulative numbers diagnosed. For women in developing countries the incidence of breast cancer is lower than in Europe or North America and thus, even with the same relative risks, the differences between the calculated results for everusers and never-users in the cumulative numbers of breast cancers diagnosed are even smaller than those shown in figure $13 .{ }^{60}$

It can be seen in figure 13 how rare breast cancer is among women in their 20 s and 30 s compared with older ages and that the excess number of cancers diagnosed in current and recent users of oral contraceptives is small in relation to the cumulative risk of breast cancer. In particular, the comparatively higher relative risk in current or recent users who began use before age 20 (figure $3 \mathrm{~b}$ ) which was used to calculate the cumulative incidence associated with oral contraceptive use from age 16 to 19 in figure 13, act at an age when the background incidence of breast cancer is low.

The calculated cumulative number of breast cancers diagnosed in 10000 women in Europe or North America in the period between starting use and 10 years after stopping is approximately 4.5 for use from age 16 to 19 compared with 4.0 in 10000 never-users of the same age over the same period; 17.5 compared with $16 \cdot 0$ for use from age 20 to $24 ; 48.7$ compared with $44 \cdot 0$ for use from age 25 to $29 ; 110$ compared with 100 for use from age 30 to $34 ; 180$ compared with 160 for use from age 35 to 39 ; and 260 compared with 230 for use from age 40 to 44 . These numbers correspond to cumulative excesses of 0.5 (SD 0.1) $1.5(0 \cdot 4), 4 \cdot 7(1 \cdot 0), 11 \cdot 1(2 \cdot 1), 21 \cdot 0(3 \cdot 6)$, and $32 \cdot 0(5 \cdot 0)$ per 10000 , respectively. ${ }^{66}$ Thus for a given duration of use, earlier use does not not lead to a greater number of cancers being diagnosed. Indeed, the calculated cumulative excess increases with increasing age at last use, and, as shown elsewhere, ${ }^{66}$ for a given age at last use the excess is little affected by a woman's prior duration of oral contraceptive use. In addition, as illustrated in figure 14, virtually all the excess cancers diagnosed up to 10 years after cessation of use are localised to the breast, and there is little or no evidence of a cumulative excess of tumours that had spread beyond the breast. ${ }^{66}$

The calculated cumulative number of breast cancers diagnosed up to 20 years after cessation of oral contraceptive use is largely influenced by the results for use that stopped between 10 and 20 years ago, because breast cancer incidence increases rapidly with age. There is no excess risk of having breast cancer diagnosed between 10 and 20 years after stopping and, indeed there may be a slight deficit in the number of breast cancers diagnosed during that period, which could offset some of the excess diagnosed up to 10 years after stopping. ${ }^{66}$ Furthermore, the cancers diagnosed between 10 and 20 years after cessation of use are less likely to have spread beyond the breast than are the cancers diagnosed in neverusers. Hence, 20 years after cessation of oral contraceptive use the difference between ever-users and never-users is not so much in the cumulative number of breast cancers diagnosed, but in the clinical presentation of the tumours. This is illustrated in figure 14 for women who used oral contraceptives from age 25 to 29 , where it can be seen that up to 20 years after cessation of use (ie, by age 50 ) there is a small excess of localised cancers and a small deficit of cancers that have spread beyond the breast but there is little difference in the total number of breast cancers diagnosed. Tumours that are localised to the breast are associated with a better survival than tumours that have spread beyond it, ${ }^{70}$ but without follow-up information on the women with breast cancer it is not possible to be sure whether oral contraceptive use increases, decreases, or has no effect on cumulative mortality from breast cancer.

As yet there is little information about use that ceased more than 20 years ago. Consequently, the conclusion from these calculations can be only that up to 20 years after cessation of use there is little difference in the cumulative incidence of breast cancer between women who have used and have not used oral contraceptives.

\section{Implications}

For women using, or contemplating the use of, oral contraceptives there is a small increase in the risk of having breast cancer diagnosed while taking oral contraceptives and during the 10 years thereafter. The older women are at last use, the larger the number of excess cancers diagnosed during this period is likely to be, although the additional cancers diagnosed are mainly ones that are localised to the breast.

For women who have used hormonal contraceptives in the past these results indicate that 10 years after cessation of use there is little or no increase in the risk of having breast cancer diagnosed, and that the cancers diagnosed are less advanced clinically than the cancers diagnosed in women who have never used oral contraceptives.

\section{Collaborators}

Members of analysis and writing committee indicated by $\star$.

American Cancer Society: E E Calle, C W Heath Jr,

H L Miracle-McMahill; Atlanta, Emory University: R J Coates, J M Liff, Aviano Cancer Center, Pordenone: S Franceschi, R Talamini; Bangkok, Mahidol University: N Chantarakul, S Koetsawang, D Rachawat; Breast Tumor Collaboration Study, Johns Hopkins University: A Morabia, L Schuman, W Stewart, M Szklo; Brisbane, University of Queensland: C Bain, F Schofield, V Siskind; British Colombia Cancer Agency: P Band, A J Coldman, R P Gallagher, T G Hislop, P Yang; Cambridge, MRC Biostatistics Unit: S W Duffy; Cancer Research Center, University of Hawaii: L M Kolonel, A M Y Nomura; Centers for Disease Control and Prevention: $\mathrm{M}$ W Oberle, $\mathrm{H}$ W Ory, $\mathrm{H}$ B Peterson, $\mathrm{H} \mathrm{G}$ Wilson, P A Wingo; Central Institute of Cancer Research, German Democratic Repulic: K Ebeling, D Kunde, P Nishan; Channing Laboratory, Brigham and Women's Hospital, Harvard Medical School: G Colditz for Nurses Health Study Research Group; Chiang Mai University: N Martin, T Pardthaisong, S Silpisornkosol, C Theetranont; Chulalongkorn University: B Boosiri, S Chutivongse, P Jimakorn, P Virutamasen, C Wongsrichanalai; CSIRO Division of Human Nutrition, Adelaide: A J McMichael, T Rohan; Danish Cancer Society: $M$ Ewertz; Dunedin, University of Otago: C Paul, D C G Skegg; European Institute of Oncology: P Boyle, M Evstifeeva; Fred Hutchinson Cancer Research Center: J R Daling, K Malone, E A Noonan, J L Stanford, D B Thomas, N S Weiss, E White; French Multicentre Breast Study, INSERM: N Andrieu, A Brêmond, F Clavel, B Gairard, J Lansac, L Piana, R Renaud; Holly Lodge: SRP Fine; Hospital General de Mexico: H R Cuevas, P Ontiveros, A Palet, S B Salazar; Hospital Universitario: N Aristizabel, A Cuadros; INSERM, Institut Gustave-Roussey, Villejuif: A Bachelot, M G Lê; Institute of Cancer Research, Sutton: J Deacon, J Peto, C N Taylor; Israel Chaim Sheba Medical Center: E Alfandary, B Modan, E Ron; Kaiser Permanente, California: G D Friedman, R A Hiatt; Leeds, ICRF Genetic Epidemiology Laboratory: T Bishop; Ljubljana, Institute of Oncology: J Kosmelj, M Primic-Zakelj,

B Ravnihar, I Stare; Loma Linda University: W L Beeson, G Fraser; London, Imperial Cancer Research Fund: D S Allen, R D Bulbrook, J Cuzick, I S Fentiman, J L Hayward, D Y Wang; Long Island Breast Cancer Study: R L Hanson, M C Leske, M C Mahoney, P C Nasca, A O Varma, A L Weinstein; Lund, University Hospital: T R Moller, H Olsson, J Ranstam; Maastricht, Univeristy of Limburg: R A Goldbohm, P A van den Brandt; Manila, University of Philippines: R A Apelo, J Baens, J R de la Cruz, B Javier, L B Lacaya, C A Ngelangel; Milan, Istituto "Mario Negri": C La Vecchia, E Negri; Milan; Istituto Nazıonale Tumori, Divisione di Statistica Medica e Biometria: E Marubini; Milan, Istituto di Statistica Medica e Biometria; M Ferraroni; Montpellier Cancer 
Centre \& INSERM: M Gerber, S Richardson, C Segala; Nairobi Centre for Research in Reproduction: D Gatei, P Kenya, A Kungu, J G Mati; National Cancer Institute, Bethesda: L A Brinton, R Hoover, C Schairer; National Institute of Child Health and Human Development, Bethesda: R Spirtas; National University of Singapore: H P Lee; Netherlands Cancer Institute: $\mathrm{M}$ A Rookus, $\mathrm{F} \mathrm{E}$ van Leeuwen for the Netherlands Oral Contraceptives and Breast Cancer Study Group; New Jersey State Department of Health; J A Schoenberg; New York, Columbia University School of Public Health: M D Gammon: Ontario Cancer Treatment \& Research Foundation: E A Clarke; Oxford, Department of Public Health \& Primary Care: L Jones, K McPherson, A Neil, M Vessey, D Yeates; Oxford, ICRF Cancer Epidemiology Unit (Secretariat): V Beral*, D Bull*, B Crossley, C Hermon, S Jones, T Key, C Lewis, G Reeves ${ }^{\star}$, P Smith; Oxford, ICRF/MRC/BHF Clinical Trial Service Unit \& Epidemilogical Studies Unit: R Collins, R Doll, R Peto ${ }^{\star}$; Royal College of General Practitioners Oral Contraception Study: P Hannaford, C Kay; San Jose, University of Costa Rica: L Rosero-Bixby; Shanghai Cancer Institute: Y-T Gao, J-M Yuan; Shanghai Institute of Planned Parenthood Research: H Y Wei, 'T Yun, C Zhiheng; Sidney, Department of Public Health: G Berry, J Cooper Booth, T Jelihovsky, R MacLennan, R Shearman; Tianjin Cancer Institute: Q-S Wang; Toronto, Department of Preventive Medicine \& Biostatistics: C J Baines, A B Miller, C Wall; Tromso University: E Lund, H Stalsberg; University of Chile: A Dabancens, L Martinez, R Molina, O Salas; University of Edinburgh: F E Alexander; University of North Carolina at Chapel Hill, School of Public Health: B S Hulka; University of Nottingham: CED Chilvers; University of Southern California: L Bernstein, R W Haile, A Paganini-Hill, M C Pike, R K Ross, G Ursin, M C Yu; University of Uppsala: H O Adami, R Bergstrom; University of Wisconsin Comprehensive Cancer Center: M P Longnecker, P Newcomb for the 4 State Study; World Health Organization, UNDP/UNFPA/WHO/World Bank Special Programme of Research Development and Training in Human Reproduction: T M N Farley, S Holck, O Meirik.

Tens of thousands of women with breast cancer and without breast cancer throughout the world have contributed to this research. This review would not have been possible without their help or without the careful collection and checking of data at each of the collaborating institutions. Central pooling and analysis was supported by the Imperial Cancer Research Fund.

\section{References}

1 Kleinman EL, ed. Hormonal contraception. London: IPPF Medical Publications, 1990.

2 Ross RK, Paganini-Hill A, Gerkins VR, et al. A case-control study of menopausal estrogen therapy and breast cancer. $\mathscr{F} A M A 1980 ; 243$ : 1635-39.

3 Pike MC, Henderson BE, Krailo MD, Duke A, Roy S. Breast cancer in young women and use of oral contraceptives: possible modyfying effect of formulation and age at use. Lancet 1983; ii: 926-30.

4 Vessey M, Baron J, Doll R, McPherson K, Yeates D. Oral contraceptives and breast cancer: final report of an epidemiologic study. Br J Cancer 1983 47: 455-62.

5 Hiatt RA, Bawol R, Friedman GD, Hoover R. Exogenous estrogen and breast cancer after bilateral oophorectomy. Cancer 1984; 54: 139-44.

6 Lê MG, Bachelot A, Doyon F, Kramer A, Hill C. Oral contraceptive use and breast cancer or cervical cancer: preliminary results of a French case-control study. In: Wolff JP, Scott JS, eds. Hormones and sexual factors in human cancer aetiology. Amsterdam: Elsevier Science Publishers, 1984

7 Talamini R, La Vecchia $\mathrm{C}$, Franceschi S, et al. Reproductive and hormonal factors and breast cancer in a Northern Italian population. Int $\mathcal{F}$ Epidemiol 1985; 14: 70-74.

8 Hislop TG, Coldman AJ, Elwood JM, Brauer G, Kan L. Childhood and recent eating patterns and risk of breast cancer. Cancer Detection Prevention 1986; 9: 47-58.

9 Meirik O, Lund E, Adami HO, Berrgstrom R, Christoffersen T, Bergsio P. Oral contraceptive use and breast cancer in young women: a joint national case-control study in Sweden and Norway. Lancet 1986; ii: $650-54$.

10 Nomura AMY, Kolonel LN, Hirohata T, Lee J. The association of replacement estrogens with breast cancer. Int $\mathcal{F}$ Cancer 1986; 37: 49-53.

11 Alexander FE, Roberts MM, Huggins A. Risk factors for breast cancer with applications to selection for the prevelance screen. $\mathcal{F}$ Epidemiol Commun Health 1987; 41: 101-06.

12 Lee NC, Rosero-Bixby L, Oberle MW, Grimaldo C, Whately AS, Rovira EZ. A case-control study of breast cancer and hormonal contraception in Costa Rica. $\mathcal{F}$ Natl Cancer Inst 1987; 79: 1247-54.

13 McPherson K, Vessey MP, Neil A, Doll R, Jones L, Roberts M. Early oral contraceptive use and breast cancer: results of another casecontrol study. Br f Cancer 1987; 56: 653-60.

14 Wang DY, De Stavola BL, Bulbrook RD, et al. The relationship between blood prolactin levels and risk of breast cancer in premenopausal women. Eur F Clin Oncol 1987; 23: 1541-48.

15 Kay CR, Hannaford PC. Breast cancer and the pill-a futher report from the Royal College of General Practitioners' Oral Contraception Study. Br $\mathcal{F}$ Cancer 1988; 58: 675-80.

16 Ravnihar B, Primic-Zakelj M, Kosmelj K, Stare J. A case-control study of breast cancer in relation to oral contraceptive use in Slovenia. Neoplasma 1988; 35: 109-21.

17 Rohan TE, McMichael AJ. Oral contraceptive agents and breast cancer: a population-based case-control study. Med $\mathcal{F}$ Aust 1988; 149: 520-26

18 Yuan J-M, Yu MC, Ross RK, Gao Y-T, Henderson BE. Risk factors for breast cancer in Chinese women in Shanghai. Cancer Res 1988; 48: 1949-53.

19 Mills PK, Beeson WL, Phillips RL, Fraser GE, Prospective study of exogenous hormone use and breast cancer in seventh-day adventists. Cancer 1989; 64: 591-97.

20 Marubini E, Decarli A, Costa A, et al. The relationship of dietary intake and serum levels of retinol and beta-carotene with breast cancer: results of a case-control study. Cancer 1988; 61: 173-80.

21 Olsson H, Moller TR, Ranstam J. Early oral contraceptive use and cancer among premenopausal women: final report from a study in southern Sweden. $\mathcal{I}$ Natl Cancer Inst 1989; 81: 1000 04 .

22 Romieu I, Willett W, Colditz G, et al. Prospective study of oral contraceptive use and the risk of breast cancer in women. $\mathcal{F}$ Natl Cancer Inst 1989; 81: 1313-21.

23 Siskind V, Schofield F, Rice D, Bain C. Breast cancer and breast feeding: results from an Australian case-control study. Am $\mathcal{F}$ Epidemiol 1989: 130: 229-36.

24 Stanford JL, Brinton LA, Hoover RN. Oral contraceptives and breast cancer: results from an expanded case-control study. $\mathrm{Br} \mathcal{F}$ Cancer 1989 ; 60: 375-81.

25 UK National Case-Control Study Group. Oral contraceptive use and breast cancer risk in young women. Lancet 1989; i: 873-82.

26 Vessey MP, McPherson K, Villard-Mackintosh L, Yeates D. Oral contraceptives and breast cancer: latest findings in a large cohort study. BrF Cancer 1989; 59: 613-17.

27 Bernstein L, Pike MC, Krailo M, Henderson BE. Update of the Los Angeles study of oral contraceptives and breast cancer: 1981 and 1983 In: Mann RD, ed. Oral contraceptives and breast cancer. Park Ridge: Parthenon Publishing, 1990: 169-81.

28 Paul C, Skegg DCG, Spears GFS. Oral; contraceptives and risk of breast cancer. Int $\mathcal{F}$ Cancer 1990; 46: 366-73

29 Schildkraut JM, Hulka BS, Wilkinson WE. Oral contraceptives and breast cancer: a case-control study with hospital and community controls. Obstet Gynecol 1990; 76: 395-402.

30 WHO Collaborative Study of Neoplasia and Steroid Contraceptives. Breast cancer and combined oral contraceptives: results from a multinational study. Br F Cancer 1990; 61: 110-19.

31 Clavel F, Andrieu N, Gairard B, et al. Oral contraceptives and breast cancer: a French case-control study. Int $\mathcal{F}$ Epidemiol 1991; 20: 32-38.

32 Segala C, Gerber M, Richardson S. The pattern of risk factors for breast cancer in a Southern France population: interest for a stratified analysis by age at diagnosis. Br $\mathcal{F}$ Cancer 1991; 64: 919-25.

33 Weinstein AL, Mahoney MC, Nasca PC, Leske MC, Varma AO. Breast cancer risk and oral contraceptive use: results from a large casecontrol study. Epidemiology 1991; 2: 353-58.

34 Wingo PA, Lee NC, Ory HW, Beral V, Peterson HB, Rhodes P. Agespecific differences in the relationship between oral contraceptive use and breast cancer. Obstet Gynecol 1991; 78: 161-70.

35 Ewertz M. Oral contraceptives and breast cancer risk in Denmark. Eur f Cancer 1992; 28A: 1176-81.

36 Lee HP, Gourley L, Duffy SW, Esteve J, Lee J, Day NE. Risk factors for breast cancer by age and menopausal status: a case-control study in Singapore. Cancer, Causes and Control 1992; 3: 313-22.

37 Miller AB, Baines CI, To T, Wall C. Canadian National Breast Scrteening Study $\mathrm{I}$, breast cancer detection and death rates among women aged 40-49 years. Can Med Assoc f 1992; 147: 1459-76.

38 Rosenberg L, Palmer JR, Clarke EA, Shapiro S. A case-control study of the risk of breast cancer in relation to oral contraceptive use. Am $\mathcal{F}$ Eprdemiol 1992; 136: 1437-44.

39 Ursin G, Aragaki CC, Paganini-Hill A, Siemiatycki J, Thompson WD, Haile RW. Oral contraceptives and premenopausal bilateral breast cancer: a case-control study. Epidemiology 1992; 3: 414-19.

40 Wang Q-S, Ross RK, Yu MC, Ning J-P, Henderson BE, Kimm HT. A case-control study of breast cancer in Tianjin, China. Cancer Epidemol Biomarkers Prevent 1992; 1: 435-39.

41 Yang CP, Daling JR, Band PR, Gallagher RP, White E, Weiss NS. Non-contraceptive hormone use and risk of breast cancer. Cancer Causes Control 1992; 3: 475-79.

42 Calle EE, Martin LM, Thun MJ, Miracle HL, Heath CW Jr. Family history, age, and risk of fatal breast cancer. Am f Epidemiol 1993; 138 $675-81$. 
43 Ngelangel CA, Lacaya LB, Cordero C, Laudico AV. Risk factors for breast cancer among Filipino women. Phil f Intern Med 1994; 32: 231-36.

44 Morabia A, Szklo M, Stewart W, Schuman L, Thomas DB. Consistent lack of association between breast cancer and oral contraceptives using either hospital or neighbourhood controls. Prevent Med 1993; 22: $178-86$.

45 Tavani A, Negri E, Franceschi S, Parazzini F, La Vecchia C. Oral contraceptives and breast cancer in Northern Italy: final report from a case-control study. Br $\mathcal{F}$ Cancer 1993; 68: 68-71.

46 Schuurman AG, van den Brandt PA, Goldbohm RA. Exogenous hormones and the risk of postmenopausal breast cancer: results from the Netherlands cohort study. Cancer Causes Control 1995; 6: 416-24.

47 Newcomb PA, Storer BE, Longnecker MP, et al. Lactation and a reduced risk of premenopausal breast cancer. $N$ Engl $\mathcal{J}$ Med 1994; 330 81-87.

48 Primic-Zakelj M, Evstifeeva T, Ravnihar B, Boyle P. Breast cancer risk and oral contraceptive use in Slovenian women aged 25 to 54 . Int $\mathcal{f}$ Cancer 1995; 62: 414_20.

49 Rookus MA, van Leeuwen FE for the Netherlands Oral Contraceptives and Breast Cancer Study Group. Oral contraceptives and risk of breast cancer in women aged 20-54 years. Lancet 1994; 344: 844-51.

50 White E, Malone KE, Weiss NS, Daling JR. Breast cancer among young US women in relation to oral contraceptive use. $\mathcal{F}$ Natl Cancer Inst 1994; 86: 505-14.

51 La Vecchia C, Negri E, Franceschi S, et al. Oral contraceptives and breast cancer: a cooperative Italian study. Int $\mathcal{F}$ Cancer 1995; 60: $163-67$.

52 Rossing MA, Stanford JL, Weiss NS, Habel LA. Oral contraceptive use and risk of breast cancer in middle-aged women. Am $\mathcal{F}$ Epidemiol (in press).

53 Brinton LA, Daling JR, Liff JM, et al. Oral contraceptives and breast cancer risk among younger women. F Natl Cancer Inst 1995; 87: $827-35$

54 Paffenbarger RS, Fasal E, Simmons ME, Kampert JB. Cancer risk as related to use of oral contraceptives during fertile years. Cancer 1977 39: 1887-91.

55 Sartwell PE, Arthes FG, Tonascia JA. Exogenous hormones, reproductive history and breast cancer. $\mathcal{F}$ Natl Cancer Inst 1977; 59: 1589-92.

56 Kelsey IL, Holford TR, White C, Mayer ES, Kilty SE, Acheson RM. Oral contraceptives and breast disease: an epidemiological study. Am $\mathcal{F}$ Epidemiol 1978; 107: 236-44.

57 Ravnihar B, Seigel DG, Lindtner J. An epidemiologic study of breast cancer and benign breast neoplasias in relation to the oral contraceptive and estrogen use. Eur F Cancer 1979; 15: 395-405.

58 Ramcharan S, Pellegrin FA, Ray RM, Hsu J-P. The Walnut Creek contraceptive drug study: a prospective study of the side effects of oral cont raceptives. In: NIH publication no 81-564. Centre for Population Research Monograph. Volume III. Bethesda: NIH, 1981 43-69.

59 Janerich DT, Polednak AP, Glebartis DM, Lawrence CE. Breast cancer and oral contraceptive use: a case-control study. $\mathcal{F}$ Chron Dis 1983 36: 639-46.

60 Brownson RC, Blackwell CW, Pearson DK, Reynolds RD, Richens $\mathrm{JW}$, Papermaster BW. Risk of breast cancer in relation to cigarette smoking. Arch Intern Med 1988; 148: 140-44.

61 Jick SS, Walker AM, Stergachis A, Jick H. Oral contraceptives and breast cancer. Br f Cancer 1989; 59: 618-21.

62 Harris RE, Zang EA, Eynder EL. Oral contraceptives and breas cancer risk: a case-control study. Int I Epidemiol 1990; 19: 240-46.

63 Wynder EL, MacCornack FA, Stellman SD. The epidemiology of breast cancer in 785 United States caucasian women. Cancer 1978; 41: 2341-54.

64 Harris NV, Weiss NS, Francis AM, Polissar L. Breast cancer in relation to patterns of oral contraceptive use. Am F Epidemiol 1982; 116: $643-51$.

65 Rosenberg L, Palmer JR, Rao RS, et al. Case-control study of oral contraceptive use and risk of breast cancer. Am F Epidemiol 1996; 143: $25-37$.

66 Collaborative Group on Hormonal Factors in Breast Cancer. Breast cancer and hormonal contraceptives: further results. Contraception (in press).

67 Mantel N. Evaluation of survival data and two new rank order statistics arising in its consideration. Cancer Chemother Rep 1966; 50: 163-70.

68 Peto Rm Pike MC, Armitage P, et al. Design and analysis of randomised clinical trials requiring prolonged observation of each patient: I introduction and design. Br F Cancer 1976; 34: 585-612.

69 Peto R, Pike MC, Armitage P, et al. Design and analysis of randomised clinical trials requiring prolonged observation of each patient: II, analysis and examples. Br $\mathcal{F}$ Cancer 1977; 35: 1-39.

70 Early Breast Cancer Trialists' Collaborative Group. Systemic treatment of early breast cancer by hormonal, cytotoxic, or immune therapy: 133 randomised trials involving 31000 recurrences and 24000 deaths among 75000 women. Lancet 1992; 339: 1-15.

71 Easton DF, Peto J, Babiker AGAG. Floating absolute risk: an alternative to relative risk in survival and case-control analysis avoiding an arbitrary reference group. Stat Med 1991; 10: 1025-35. 